\title{
Metagenomes and metatranscriptomes shed new light on the microbial-mediated sulfur cycle in a Siberian soda lake
}

\author{
Charlotte D. Vavourakis ${ }^{1}$, Maliheh Mehrshad ${ }^{2}$, Cherel Balkema ${ }^{1}$, Rutger van Hall ${ }^{3}$, Adrian-Ştefan Andrei ${ }^{2}$, \\ Rohit Ghai ${ }^{2}$, Dimitry Y. Sorokin ${ }^{4,5}$ and Gerard Muyzer ${ }^{1 *}$ (D)
}

\begin{abstract}
Background: The planetary sulfur cycle is a complex web of chemical reactions that can be microbial-mediated or can occur spontaneously in the environment, depending on the temperature and $\mathrm{pH}$. Inorganic sulfur compounds can serve as energy sources for specialized prokaryotes and are important substrates for microbial growth in general. Here, we investigate dissimilatory sulfur cycling in the brine and sediments of a southwestern Siberian soda lake characterized by an extremely high $\mathrm{pH}$ and salinity, combining meta-omics analyses of its uniquely adapted highly diverse prokaryote communities with biogeochemical profiling to identify key microbial players and expand our understanding of sulfur cycling under haloalkaline conditions.

Results: Peak microbial activity was found in the top $4 \mathrm{~cm}$ of the sediments, a layer with a steep drop in oxygen concentration and redox potential. The majority of sulfur was present as sulfate or iron sulfide. Thiosulfate was readily oxidized by microbes in the presence of oxygen, but oxidation was partially inhibited by light. We obtained 1032 metagenome-assembled genomes, including novel population genomes of characterized colorless sulfuroxidizing bacteria (SOB), anoxygenic purple sulfur bacteria, heterotrophic SOB, and highly active lithoautotrophic sulfate reducers. Surprisingly, we discovered the potential for nitrogen fixation in a new genus of colorless SOB, carbon fixation in a new species of phototrophic Gemmatimonadetes, and elemental sulfur/sulfite reduction in the "Candidatus Woesearchaeota." Polysulfide/thiosulfate and tetrathionate reductases were actively transcribed by various (facultative) anaerobes.
\end{abstract}

Conclusions: The recovery of over 200 genomes that encoded enzymes capable of catalyzing key reactions in the inorganic sulfur cycle indicates complete cycling between sulfate and sulfide at moderately hypersaline and extreme alkaline conditions. Our results suggest that more taxonomic groups are involved in sulfur dissimilation than previously assumed.

Keywords: Soda lake, Haloalkaliphiles, Metagenomics, Metatranscriptomics, Thiosulfate, Tetrathionate, Polysulfide, Woesearchaeota, Gemmatimonadetes, Nitrogen fixation

\section{Background}

Since the dawn of unicellular life, the dissimilation of sulfur compounds by specialized prokaryotes forms an important part of the planetary biogeochemical cycle of sulfur [1-3]. For instance, microbial sulfide oxidation lies at the base of the food chain in the ecosystems

\footnotetext{
* Correspondence: G.Muijzer@uva.nl

${ }^{1}$ Microbial Systems Ecology, Department of Freshwater and Marine

Microbiology, Institute for Biodiversity and Ecosystem Dynamics, University of

Amsterdam, P.O. Box 94240, 1090 GE Amsterdam, the Netherlands

Full list of author information is available at the end of the article
}

associated with hydrothermal vents in the deep sea [4], and sulfate reducers are the primary degraders of organic material in the seabed where oxygen is depleted [5]. A variety of stable intermediary inorganic sulfur compounds are biologically available in between the end members of the sulfur cycle, free dissolved sulfide $\left(\mathrm{\Sigma H}_{2} \mathrm{~S}=\right.$ $\left.\mathrm{H}_{2} \mathrm{~S}+\mathrm{HS}^{-}+\mathrm{S}^{2-}\right)$, and sulfate $\left(\mathrm{SO}_{4}{ }^{2-}\right)$. In addition, different temperature- and $\mathrm{pH}$-dependent abiotic conversions occur; sulfur can react with other elements and can be

(c) The Author(s). 2019 Open Access This article is distributed under the terms of the Creative Commons Attribution 4.0 International License (http://creativecommons.org/licenses/by/4.0/), which permits unrestricted use, distribution, and reproduction in any medium, provided you give appropriate credit to the original author(s) and the source, provide a link to the Creative Commons license, and indicate if changes were made. The Creative Commons Public Domain Dedication waiver (http://creativecommons.org/publicdomain/zero/1.0/) applies to the data made available in this article, unless otherwise stated. 
cycled in between organic and inorganic compounds, rendering the biogeochemical cycle of sulfur quite complex.

Hypersaline soda lakes are evaporative terrestrial lakes with total salt concentrations above $50 \mathrm{~g} \mathrm{~L}^{-1}$ and a stable high $\mathrm{pH}$ roughly around $10[6,7]$. These unique environmental conditions form a strong selective force and microbes adapted to these double extremes are called "haloalkaliphiles." Driven by high sulfate concentrations and primary productivity in the brines, the inorganic sulfur cycle is one of the most active cycles occurring in soda lakes [7-11]. At high $\mathrm{pH}, \Sigma \mathrm{H}_{2} \mathrm{~S}$ occur mainly in the deprotonated hydrosulfide form $\left(\mathrm{HS}^{-}\right)$. Sulfide oxidation and sulfide production by reduction of sulfur compounds and the degradation of organic sulfur, i.e., sulfidogenesis, are therefore not hampered by the buildup of toxic $\mathrm{H}_{2} \mathrm{~S}$, as is the case in environments with acidic or neutral $\mathrm{pH}$ [8]. Due to the high alkalinity, increased chemical stability of polysulfides $\left(\mathrm{S}_{n}{ }^{2-}\right)$ in anoxic sediments also results in relatively higher rates of sulfur-polysulfide respiration compared to dissimilatory sulfate reduction. At moderate salinities $(\sim$ $50-250 \mathrm{~g} \mathrm{~L}^{-1}$ total salt), a complete sulfur cycle between $\Sigma \mathrm{H}_{2} \mathrm{~S}$ and $\mathrm{SO}_{4}{ }^{2-}$ is proposed to occur, whereas at saltsaturating conditions, the cycle is likely short-circuited by the presence of sulfur intermediates such as elemental sulfur $\left(\mathrm{S}^{0}\right)$, polysulfides $\left(\mathrm{S}_{n}{ }^{2-}\right)$, and thiosulfate $\left(\mathrm{S}_{2} \mathrm{O}_{3}{ }^{2-}\right)[8]$.

Except for phototrophic green sulfur bacteria (family Chlorobiaceae), haloalkaliphilic representatives have been isolated for all known functional groups involved in the dissimilatory inorganic sulfur cycle [7-10]. Purple sulfur bacteria from the genera Halorhodospira and Ectothiorhodospira (class Gammaproteobacteria) that use light energy and some reduced sulfur compounds for anoxygenic photosynthesis are also commonly found in other high-salinity environments with neutral $\mathrm{pH}$ [12]. However, most genera appear to be unique for soda lakes and industrial haloalkaline environments [10], such as the chemolithoautotrophic sulfur-oxidizing bacteria (SOB) from the genus Thioalkalivibrio (class Gammaproteobacteria) that can use diverse reduced sulfur compounds as electron donors and bacteriochlorophyll- $a$ containing lithoheterotrophic SOB from the genera Roseinatronobacter and Rhodobaca (class Alphaproteobacteria) that can use sulfur compounds as an additional energy source. The known genera of the soda lake sulfidogens, which perform sulfate reduction, elemental sulfur/polysulfide or thiosulfate reduction, and disproportionation, all appear to be obligate haloalkaliphiles [7]. Recently, it has been discovered that also the members of the extremely haloalkaliphilic Euryarchaeota can participate in dissimilatory sulfur respiration in anaerobic sediments of hypersaline soda lakes [13].

Despite the broad interest in the global biogeochemical cycle of sulfur, the genetic makeup of the microbes involved especially in the oxidative part of the cycle and those that disproportionate intermediary compounds is not yet fully understood [14-18]. Both phototrophic and chemotrophic sulfur oxidizers share the same enzymes for sulfur transformations $[19,20]$. The best described pathway of thiosulfate oxidation to $\mathrm{SO}_{4}{ }^{2-}$ occurs through the "Sox" enzyme system, with SoxAX, SoxYZ, SoxB, and SoxCD as the essential components [21]. Intermediary storage of zero-valent sulfur in sulfur globules occurs only under suboptimal environmental conditions in organisms that lack SoxCD [22]. Further oxidation of the zero-valent sulfur can involve several other enzymes, such as a reversed dissimilatory sulfite reductase (rDSR), sulfate adenylyltransferase together with adenylyl-sulfate reductase (Sat/Apr), and sulfite dehydrogenases (SOR/SOE), but uncertainties remain as many SOB lack the rDSR [14]. Two alternative pathways for thiosulfate oxidation have been described that involve the formation of tetrathionate $\left(\mathrm{S}_{4} \mathrm{O}_{6}{ }^{2-}\right)$ which include the quinone-interacting doxAD/TETH system described in the acidophilic elemental sulfur-oxidizing archaeon Acidianus ambivalens [23] or the cytochrome $c$-dependent tsdAB-encoded thiosulfate dehydrogenase in Allochromatium vinosum [24, 25].

Several sulfur intermediates can be cycled through combined microbial-chemical processes in an intraspecies sulfur cycle. For instance, certain heterotrophic members of the Gammaproteobacteria oxidize $\mathrm{S}_{2} \mathrm{O}_{3}{ }^{2-}$ to $\mathrm{S}_{4} \mathrm{O}_{6}{ }^{2-}$ in soda lakes. The $\mathrm{S}_{4} \mathrm{O}_{6}{ }^{2-}$ is released by the cells and can act as an oxidant on $\Sigma \mathrm{H}_{2} \mathrm{~S}$ in the environment leading to the formation of $\mathrm{S}^{0}$ and the regeneration of $\mathrm{S}_{2} \mathrm{O}_{3}{ }^{2-}$ [26]. Intraspecies sulfur cycling is also proposed to occur with bacterial $\mathrm{S}^{0}$ and $\mathrm{S}_{2} \mathrm{O}_{3}{ }^{2-}$ reduction catalyzed by polysulfide/thiosulfate reductases ( $p s r / p h s$ genes) in several neutrophilic model organisms [27-29]. Polysulfides formed by the reaction of $\mathrm{S}^{0}$ and $\mathrm{HS}^{-}$are reduced in the periplasm of Wolinella succinogenes (class Epsilonproteobacteria) to $\mathrm{HS}^{-}$and $\mathrm{S}_{n-1}{ }^{2-}$, after which the $\mathrm{HS}^{-}$diffuses out of the cell and reacts again with $\mathrm{S}^{0}$ to form $\mathrm{S}_{n}{ }^{2-}$ [28]. Recently, a $p s r A / p h s A$ orthologous gene was also identified in the genome of the haloalkaliphilic sulfidogen Desulfurivibrio alkaliphilus $\mathrm{AHT}^{\mathrm{T}}$ [30], an organism that can perform elemental sulfur (polysulfide) disproportionation [18].

While more physiological studies of novel isolates and enzyme characterizations are necessary to close the knowledge gaps that remain in the sulfur biogeochemical cycle, culture-independent methods in combination with in situ rate measurements help to pinpoint where significant gaps still exist. Direct sequencing of environmental DNA or RNA, i.e., metagenomics and metatranscriptomics, which avoid the bottleneck of cultivation, has the potential to characterize the genetic capabilities and regulation of gene expression in novel, uncultivated organisms. Previous meta-omics studies on hypersaline soda lakes have targeted 
the sulfur cycle mainly through the detection of functional marker genes or their transcripts rather than focusing on the reconstruction of metagenome-assembled genomes (MAGs) [31-33] or have focused on the MAGs of only the most abundant uncultured microbes present in soda lake brines or sediments [34,35].

Here, we investigated the inorganic sulfur cycle in Cock Soda Lake (Kulunda Steppe, southwestern Siberia, Russia). We chose this lake specifically because in contrast to the smaller lakes in its close vicinity, it has a relatively stable water regime with a moderately hypersaline brine $\left(50-120 \mathrm{~g} \mathrm{~L}^{-1}\right.$ salt, $\left.\mathrm{pH} 10\right)$ where a complete sulfur cycle could occur. We identified for 1032 newly recovered MAGs from the brine and sediments which prokaryotes encode marker genes for oxidative and reductive branches of the dissimilatory sulfur cycle. Further, transcription by putative sulfur-cycling prokaryotes was investigated using both sequencing of the RNA from the metatranscriptome and sequencing amplicons of $16 \mathrm{~S}$ rRNA gene transcripts from samples of the top sediment layer.

\section{Results}

\section{Biogeochemical profile of Cock Soda Lake}

The total salinity of the Cock Soda Lake brine in July 2016 was $55 \mathrm{~g} \mathrm{~L}^{-1}$, and the soluble carbonate alkalinity was 0.62 $\mathrm{M}$. Based on the measured chloride ion concentrations and inorganic carbon, we inferred that the total salinity decreased only slightly in the pore water of the sediments below $2 \mathrm{~cm}$ depth (Additional file 1: Figure S1). The $\mathrm{pH}$ of the brine and the pore water of the top $2 \mathrm{~cm}$ sediment layer was 9.9 (Additional file 2: Figure S2). The brine was green in color, teeming with live brine shrimps and strongly mixed by wind. The larvae of the soda fly Ephydra hyans [36] actively perturbed the top layer of the sediment, which was covered by a thin fluffy green mat. Organic carbon contents in the surface $4 \mathrm{~cm}$ were $>1 \%$ and decreased to approximately $0.5 \%$ in the sediments below $4 \mathrm{~cm}$ (Fig. 1a). Nucleic acid isolation yields were 13-274x higher from samples taken from the top 2 and 5 $\mathrm{cm}$ sediment layers compared to deeper layers. The top $12 \mathrm{~cm}$ of the sediment matrix consisted of silty sand with a mean grain size of $123 \mu \mathrm{m}$ and a bimodal distribution of mostly very fine or medium sand grains and $20 \%$ silt (i.e., particles $<63 \mu \mathrm{m}$; Additional file 3: Table S1). The top 12 $\mathrm{cm}$ sediment fraction was rich in iron $(\sim 6-8 \mathrm{~g} / \mathrm{kg})$, phosphorus $(\sim 130-200 \mathrm{mg} / \mathrm{kg})$, and manganese $(\sim 120-190$ $\mathrm{mg} / \mathrm{kg}$ ) (Additional file 3: Table S2). In the brine and the top $2 \mathrm{~cm}$ of the sediments, most of the measured sulfur compounds were present as sulfate ions (Fig. 1a). Deeper in the sediments, total sulfur content (ICP-OES) decreased and was mainly in the form of acid-volatile iron sulfides (FeS). Traces of $\mathrm{S}_{2} \mathrm{O}_{3}{ }^{2-}$ were measured only in the surface sediment ( $\sim 40 \mu \mathrm{M}$ and $\sim 20 \mu \mathrm{M}$ in the $0-2$-cm and $2-4$ - $\mathrm{cm}$ layer, respectively) from which enough pore water could be extracted. Nitrate concentrations in the pore water could only be quantified in the 2-4-cm sediment layer $(\sim 100 \mu \mathrm{M}$; Additional file 1: Figure S1a). No free hydrogen sulfide $\left(\mathrm{HS}^{-}\right)$could be detected. The highest methane concentration was measured in the brine, but it was detectable throughout the whole sediment column as well. The redox potential dropped steeply in the first centimeter of sediments, a layer with a distinct brown coloration, and gradually decreased to approximately 400 Eh at 3.5-cm sediment depth (Fig. 1b). The dissolved oxygen concentration in the pore water dropped below detection in the top $2-4 \mathrm{~mm}$ of sediments.

The rates of microbial thiosulfate consumption in the 0-2-cm and 2-4-cm sediment layers were comparable (Fig. 1c). Two- to sevenfold higher rates of $\mathrm{S}_{2} \mathrm{O}_{3}{ }^{2-}$ consumption were observed at millimolar compared to micromolar concentrations. For the experiments in the millimolar range, $\mathrm{S}_{2} \mathrm{O}_{3}{ }^{2-}$ was completely oxidized to $\mathrm{SO}_{4}{ }^{2-}$ (1:2 $\mathrm{M}$ ratios) in the top 2-cm sediment layer both in the light and the dark, but the relatively higher rates obtained under dark conditions suggest partial inhibition by light. In the 2-4-cm sediment layer, the measured $\mathrm{S}_{2} \mathrm{O}_{3}{ }^{2-}$ to $\mathrm{SO}_{4}{ }^{2-}$ ratio shifted to $1: 4$, because more reduced sulfur compounds (most probably FeS) were additionally oxidized upon oxygen exposure.

\section{Prokaryotic community profiles in the brine and top 25 cm of sediments}

The brine and sediment prokaryotic community profiles obtained by $16 \mathrm{~S}$ rRNA gene amplicon sequencing were very different (Fig. 2a). Community diversity at the level of genus increased from the brine down to a depth of $15 \mathrm{~cm}$ in the sediments. A steep drop in the total number of observed OTUs ( richness) and Shannon diversity was found in the 15-25-cm sediment layer (Fig. 2b), which coincided with a steep increase in the amount of FeS at this depth (Fig. 1a). The most abundant genus in the brine was Nitrincola (Gammaproteobacteria), which contains haloalkaliphilic, facultative anaerobic isolates capable of nitrate reduction [37] (Fig. 2a). The 50 most abundant genera amounted to a total relative abundance of $\sim 80-90 \%$ of the prokaryotic community in every sediment layer. Those OTUs assigned to the genera known to be involved in dissimilatory cycling of inorganic sulfur compounds [7] were relatively more abundant in the sediment. Only the SOB genera Thioalkalimicrobium (reclassified recently into Thiomicrospira [38], Gammaproteobacteria), Rhodobaca, and Roseinatronobacter (Alphaproteobacteria) were predominantly found in the brine ( 15,7 , and $2 \%$, respectively). Chemolithoautotrophic SOB from the genus Thioalkalivibrio were highly abundant at every sediment depth $(\sim 5-15 \%)$, while the genera Thiohalospira, Thioalkalibacter, Thioalkalispira (Gammaproteobacteria), and Sulfurimonas (Epsilonbactereota) were 


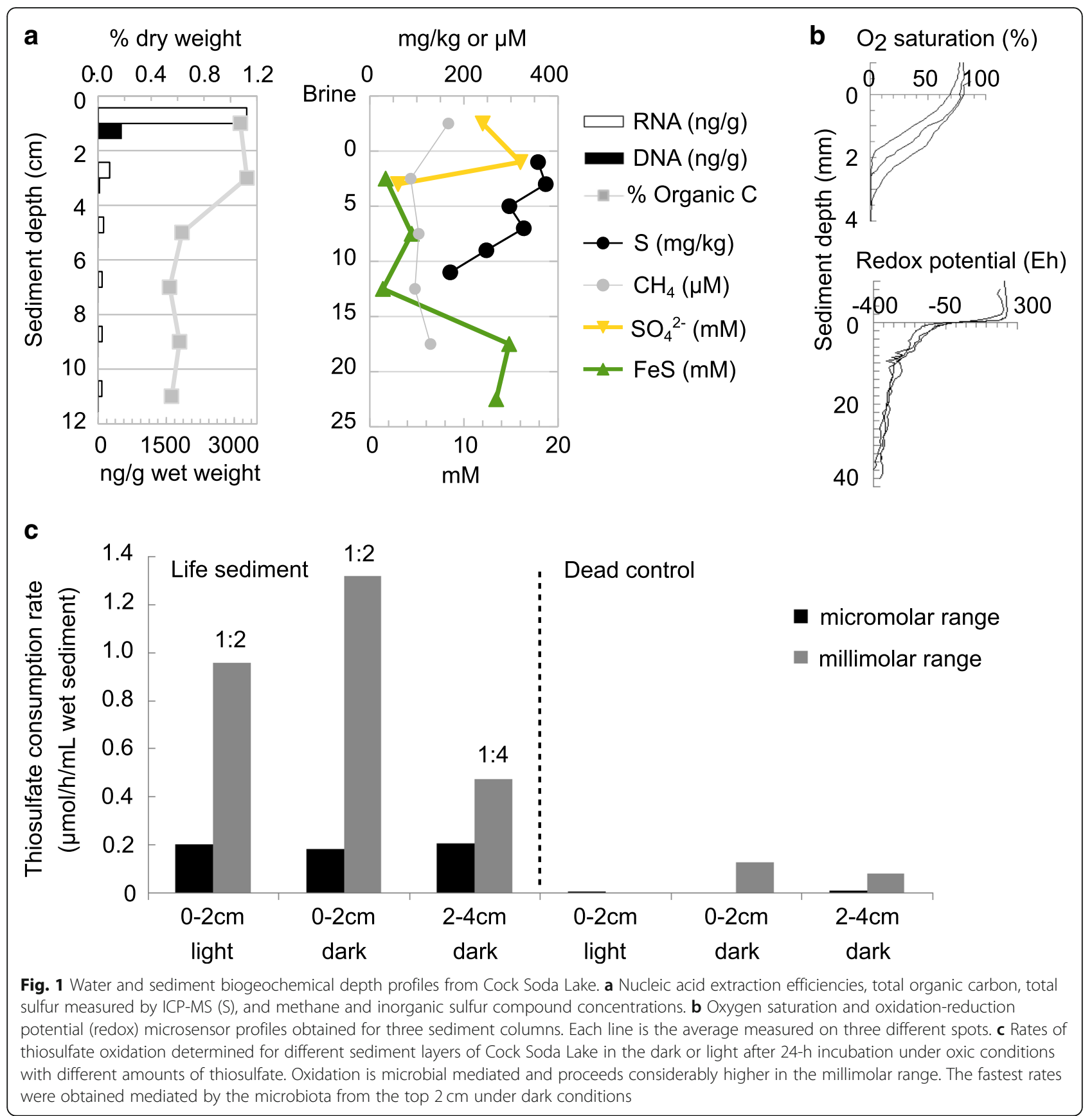

relatively more abundant deeper in the sediment. The most abundant genus at 15-25-cm sediment depth $(\sim 21-23 \%)$ was Halomonas, from which haloalkaliphilic isolates can oxidize thiosulfate to tetrathionate [26]. The second most abundant genus in the deepest sediment layers was an uncultured group SCGC-AB-539-J10 within the Chloroflexi ( 9-12\%, Dehalococcoidia). The members of this group are also found in marine subsurface sediments, but their exact ecological role remains to be determined [39]. Lithoautotrophic sulfate-reducing bacteria (SRB) from the genera Desulfonatronovibrio and Desulfonatronospira
(Deltaproteobacteria) and sulfur/thiosulfate reducers capable of lithoauthotrophic polysulfide disproportionation from the known genera Desulfurivibrio (Deltaproteobacteria) and Dethiobacter (Firmicutes) constituted together a significant portion of the total community in every sediment layer $(\sim 3-4 \%)$.

High-throughput genome recovery from the brine and top layer of sediments

We reconstructed in total 1032 novel MAGs from the brine and top layers $(0-2$ and $0-5 \mathrm{~cm})$ of the sediments, 


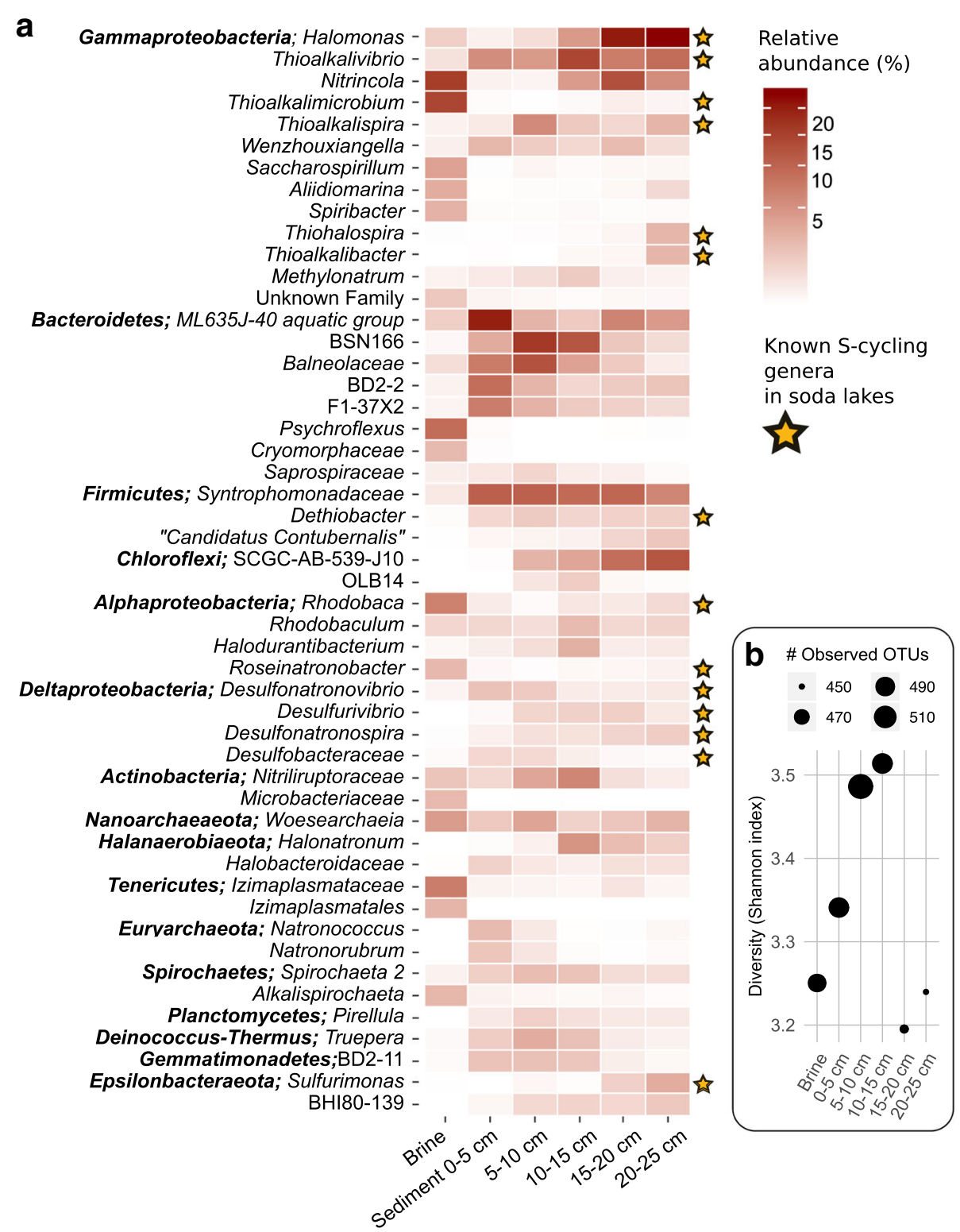

Fig. 2 a Average relative abundance of the top 50 abundant genera or OTUs in Cock Soda Lake identified by 165 rRNA gene amplicon sequencing. The minimum relative abundance shown is $0.1 \%$ (white). The yellow stars indicate the genera from which soda lake isolates were previously characterized that have the ability to transform inorganic sulfur compounds. $\mathbf{b}$ Richness and diversity of the prokaryote communities in the soda lake brine and at different sediment depths

among which 232 were high-quality drafts (CheckMcompleteness $\geq 90 \%$, CheckM-contamination $<5 \%$ ) (Additional file 4: Dataset 1) [40]. The MAGs were assigned to at least 28 different phyla (Fig. 3). About half of the MAGs were classified as Proteobacteria (288), Bacteroidetes (191), and Firmicutes (117), which is in agreement with the dominant phyla found in the $16 \mathrm{~S}$ rRNA gene amplicon sequencing datasets (Fig. 2). Within the Bacteroidetes and Firmicutes, most MAGs were assigned the same taxonomy (Additional file 4: Dataset 1) as the major dominant OTUs in the top $5 \mathrm{~cm}$ of sediments (Fig. 2), namely the ML635J-40 aquatic group (SILVA database) and the Syntrophomonadaceae, respectively, putative haloalkaliphilic groups commonly detected in soda lakes [35]. The latter family members might be reversed acetogens, able to oxidize acetate in syntrophy with methanogens or SRB, or they might be hydrogenotrophic acetogens $[35,41]$. The most abundant $16 \mathrm{~S}$ rRNA gene transcripts were assigned to Nodosilinea (relative abundance $\sim 17 \%$; a genus of haloalkaliphilic, filamentous benthic Cyanobacteria [42, 43]) in the $0-2-\mathrm{cm}$ layer of sediments and to Nitriliruptoraceae ( 17\%; a 


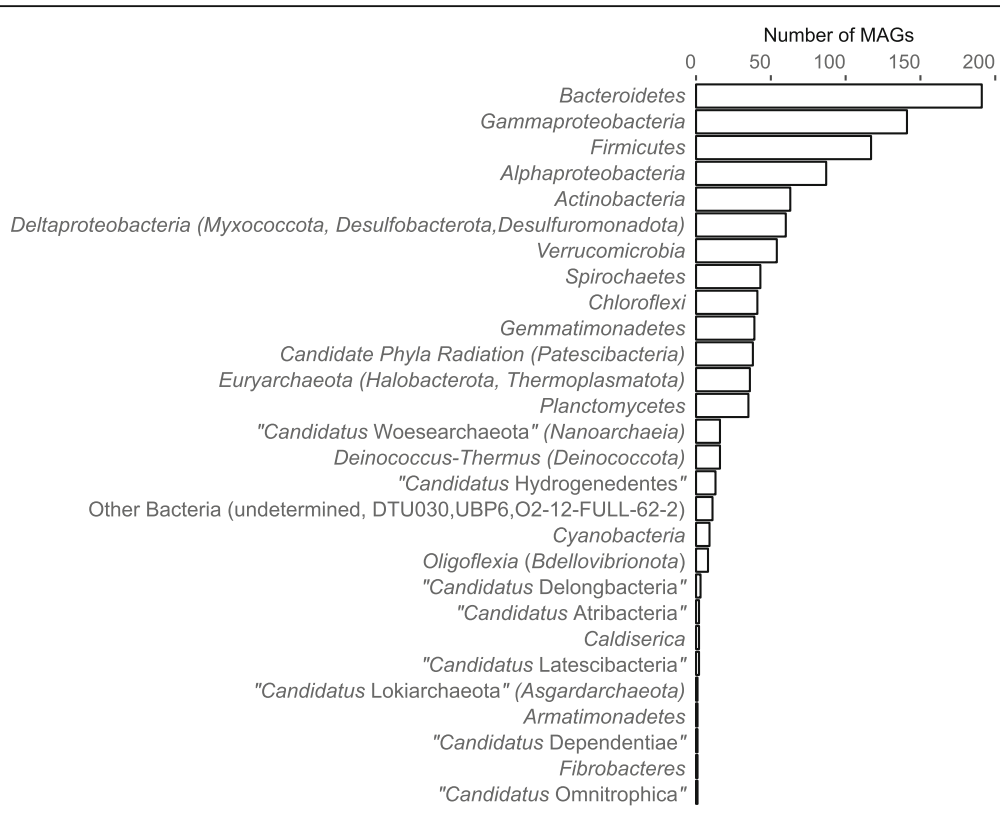

Fig. 3 Phylogeny (phylum/class level) of the 1032 novel metagenome-assembled genomes (MAGs) obtained from Cock Soda Lake in this study. In the brackets are the phylum- or class-level "GTDB" taxonomic names indicated according to [89]

family of putative nitrile-hydrolyzing Actinobacteria [44]) in the 2-4-cm layer (Additional file 5: Figure S3), groups from which we recovered 1 and 38 different MAGs, respectively (Additional file 4: Dataset 1 ).

Six MAGs could not be classified to any known phylum using the Genome Taxonomy Database (GTDB) ("Other Bacteria, undetermined"; Fig. 3). Based on the phylogeny of 16S rRNA genes (Additional file 4: Dataset 1) and conserved ribosomal proteins (Additional file 6: Dataset 2), four out of six unclassified MAGs (bin. CSSed162cmB.61, bin. CSSed $165 \mathrm{~cm} .362$, bin. CSSed $165 \mathrm{~cm} .369$, and bin. CSSed $165 \mathrm{~cm} .452)$ were closely affiliated with the bacterial candidate division BRC1 and the remaining two MAGS (bin. CSSed $165 \mathrm{~cm} .289$ and bin. CSSed $165 \mathrm{~cm} .465$ ) were distantly related to the uncultured group LD1-PA32 (Chlamydiae).

\section{Metagenome-assembled genomes and transcriptional activity of dissimilatory sulfur prokaryotes}

Among the 1032 new MAGs and 401 MAGs obtained previously from the Cock Soda Lake sediments [35, 45], we have identified 1 archaeal and 219 bacterial MAGs that represent separate species based on average nucleotide identity (ANI) and are derived from prokaryotes with the potential for the dissimilation of sulfur compounds based on the presence of sulfur cycle marker genes (Fig. 4; Additional file 7: Dataset 3). Some MAGs were assigned to unexpected taxonomic and functional groups (summarized in Table 1).

We obtained 1 metatranscriptome from the top 2-cm sediment layer [46], while from the deeper sediment layers, only a small amount of RNA could be extracted. Although ribosomal RNA (rRNA) was removed from the metatranscriptome before sequencing, still about $\sim 42 \%$ reads were of ribosomal origin. In addition, several other structural, non-coding RNAs (ncRNA) were sequenced, most abundantly bacterial ribonuclease P (RnaseP) class A $(\sim 7 \%$ of ncRNA), transfer-messenger RNA (tmRNA, 3\%), and Ornate Large Extremophilic RNA (OLE RNA, 1\%; Additional file 8: Figure S4). Metatranscriptomic reads not originating from rRNA were assembled into 1,056,676 contigs of minimum $200 \mathrm{bp}$ length, comprising in total 1,419, 467 coding sequences [47]. Within KEGG, 17,880 hits were found to enzymes involved in energy metabolism, among which 1334 involved in nitrogen metabolism and 1717 in sulfur metabolism (Additional file 9: Figure S5). A total of 1498 unique transcripts (contigs $>100$ AA) gave hits to an extended set of marker genes for dissimilatory sulfur cycling (Fig. 5).

\section{SRB and thiosulfate/polysulfide reductases}

All species representatives that encoded the full canonical pathway for sulfate reduction (sat+aprAB+dsrAB) were Deltaproteobacteria (Fig. 4). Genes for a quinoneinteracting membrane-bound oxidoreductase complex ( $q m o A B C)$, which is suggested to be essential for sulfate reduction in deltaproteobacterial SRB [48], were present in these MAGs as well (Additional file 10: Dataset 4). $A p r A$, aprB, sat, and $d s r B$ ranked as the most abundantly transcribed marker genes for dissimilatory sulfur transformations that were investigated (summed RPKG of individual metatranscriptomic contigs; Fig. 5a). The 
"Ca. Woesearchaeota" arc. - 1 Nannocystales bac. - 1 Myxococcales bac. - 1 Geopsychrobacteraceae bac. - 1 Desulfurivibrio sp. - 1 Desulfosarcinaceae bac. - 1 Desulfonatronum sp. - 2 Desulfonatronovibrio sp. - 4 Desulfonatronospira sp. - 4

Desulfococcaceae bac. - 1

Desulfobulbaceae bac. - 2

Desulfobacterales bac. - 4

Desulfobacteraceae bac. - 2

Syntrophobacteraceae bac. - 1

Thermaerobacteria bac. - 2 Halarsenatibacteraceae bac. - 1 Firmicutes bac. - 4

Syntrophomonadaceae bac. - 8 Dethiobacteria bac. - 9 Tindallia sp. - 1 Clostridiaceae bac. - 1 Clostridia bac. - 2 Spirochaetales bac. - 5 Spirochaetaceae bac. - 5 Ignavibacteriales bac. - 1 Dehalococcoidia bac. - 2 Nitriliruptorales bac. - 3 Egibacter sp. -1

Nitriliruptoraceae bac. - 13

Bacteroidetes bac. - 4

Bacteroidales bac. - 12 Lishizhenia sp. - 1 Flavobacteriales bac. - 1 Cryomorphaceae bac. - 1 Cecembia sp. - 1

Waddliaceae bac. - 1

Trueperaceae bac. - 8 Gemmatimonadetes bac. - 9

Puniceicoccaceae bac. - 1 Opitutales bac. - 2 Opitutae bac. - 1 "Ca. Handelsmanbacteria bac." - 1 Kiritimatiellae bac. - 2 bac. (unclassified) - 1

Wenzhouxiangella sp. - 2

Thiotrichales bac. - 1 Saccharospirillaceae bac. - 2

Methylophaga sp. - 1

Methylomicrobium sp. - 1

Aquisalimonadaceae bac. - 4

Pseudomonadales bac. - 4

Pseudomonas sp. - 1
Marinospirillum sp. - 2 Marinospirillum sp. -2
Halomonas sp. -6 Ectothiorhodospiraceae bac. - 1

Alkalilimnicola sp. - 1

Halorhodospira sp. - 2

Sedimenticolaceae bac. - 1

Thiorhodovibrio sp. -1

Gammaproteobacteria bac. - 10

Thiohalomonadaceae bac. - 1

Chromatiaceae bac. - 2

Thiohalocapsa sp. - 1

Thioalkalivibrio sp. - 8

Rhizobiales bac. - 1

Rubritepida sp. - 1

Geminicoccales bac. Geminicoccaceae bac. - 1
Roseinatronobacter thiooxidans - 1
Roseovarius sp. -1 Roseinatronobacter thiooxidans - 1
Roseovarius sp. -1
Rhodobacteraceae bac -24

Rhodobaca sp. - 1

Natronohydrobacter sp. - 6

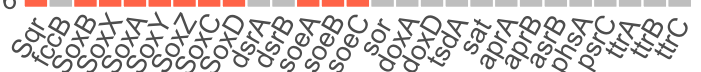

\section{Reduction/disproportionation}

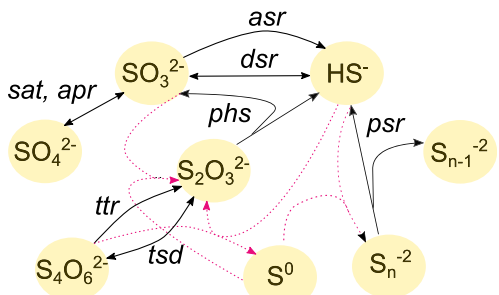

Occurrence

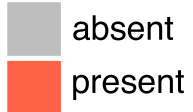

\section{Oxidation}

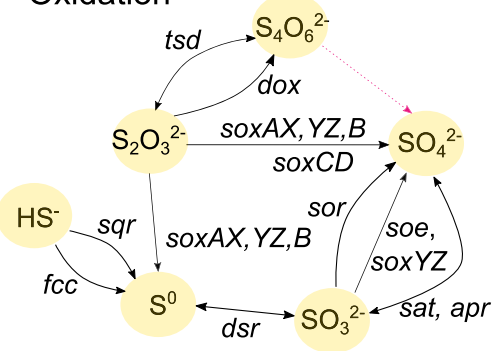

Fig. 4 Overview pathways involved in dissimilatory inorganic sulfur compound cycling encoded by the selected MAGs. The presence/absence of functional marker genes in the MAGs is given by the color scheme. The genomes were grouped by phylogeny, and the number of species representatives assessed for each group is given after its taxonomic name. The involvement of each gene in specific pathways is indicated in the diagrams. Full arrows indicate the enzymatic reactions for which genes were found encoded in the metagenomes. The dotted, pink arrows show possible chemical reactions 
Table 1 Description of high-quality MAGs from species representatives with novel metabolic potential

\begin{tabular}{|c|c|c|c|c|}
\hline Name & GC & $\mathrm{Cmpl}$ & Cont & Novelty \\
\hline Rhodobacteraceae bac. CSBr16_160 & 60 & 88 & 0.5 & $\begin{array}{l}\text { New genus of a photoheterotrophic SOB in the family Rhodobacteraceae. } \\
\text { Genes for aerobic CO oxidation }\end{array}$ \\
\hline Gemmatimonadetes bac. CSSed162cmB_429 & 68 & 99 & 3.9 & $\begin{array}{l}\text { First phototroph with the potential for carbon fixation in the phylum } \\
\text { Gemmatimonadetes } \\
\text { Putative role in the sulfur cycle (soxCD) and potential for dissimilatory } \\
\text { nitrate reduction to ammonia }\end{array}$ \\
\hline Thiohalomonadaceae bac. CSSed162cmB_532 & 61 & 92 & 1.7 & $\begin{array}{l}\text { New genus of colorless SOB in the family Thiohalomonadaceae (GTDB } \\
\text { taxonomy). Genes for } \mathrm{N}_{2} \text { fixation }\end{array}$ \\
\hline Flavobacteriales bac. CSSed162cmB_293 & 53 & 95 & 0.5 & $\begin{array}{l}\text { New haloalkaliphilic genus within the Bacteroidetes with potential for } \\
\mathrm{S}_{2} \mathrm{O}_{3}{ }^{2-} \text { oxidation to } \mathrm{S}_{4} \mathrm{O}_{6}{ }^{2-} \text { (doxAD) }\end{array}$ \\
\hline "Ca. Woesearchaeota" arch. CSSed165cm_557 & 41 & 81 & 0 & $\begin{array}{l}\text { New genus within the candidate phylum Woesearchaeota. Putative } \\
\mathrm{S}^{0} / \mathrm{SO}_{3}^{2-} \text { reducer }\end{array}$ \\
\hline Alkalilimnicola sp. CSSed162cmA_191 & 67 & 87 & 0.9 & $\begin{array}{l}\text { Well-characterized haloalkaliphilic genus of } \mathrm{SOB} \text { within the } \\
\text { Gammaproteobacteria, new is potential for } \mathrm{S}_{4} \mathrm{O}_{6}{ }^{2-} \text { reduction. Facultative } \\
\text { autotroph and facultative anaerobe. Genes for aerobic } \mathrm{CO} \text { oxidation and } \\
\text { dissimilatory nitrate reduction to nitrite }\end{array}$ \\
\hline Geopsychrobacteraceae bac. CSSed162cmA_454 & & 94 & 1.9 & $\begin{array}{l}\text { New haloalkaliphilic genus within the class Deltaproteobacteria. Facultative } \\
\text { anaerobe with potential for } \mathrm{S}_{4} \mathrm{O}_{6}{ }^{2-} \text { reduction and } \mathrm{N}_{2} \text { fixation }\end{array}$ \\
\hline
\end{tabular}

GC average G+C mol\%, Cmpl \% CheckM-completeness, Cont \% CheckM-contamination

majority of the $d s r B$ transcripts originated from Deltaproteobacteria and especially known haloalkaliphilic lithotrophic SRB (Fig. 5b). We found a highly active transcription of $d s r B$ assigned to a putative new genus within the family Desulfococcaceae (GTDB taxonomy, former Desulfobacteraceae) and transcribed from the corresponding MAGs that seem most closely related to the genus Desulfonema based on the phylogeny of 16 ribosomal proteins (Additional file 6: Dataset 2). Although less abundant, transcripts from a reversed type DSR assigned to gammaproteobacterial SOB were also recovered. The relative abundance of $16 \mathrm{~S}$ rRNA gene transcripts assigned to several deltaproteobacterial SRB groups (Desulfobacteraceae, Desulfonatronovibrio, Desulfonatronospira, Desulfonatronobacter) was higher in the 0-2-cm compared to the 2-4-cm layer of sediments (Additional file 5: Figure S3).

Most of the deltaproteobacterial MAGs encoded for dissimilatory ammonifying nitrite reductases (NrfAH; Additional file 10: Dataset 4). A partial dissimilatory periplasmic nitrate reductase (napA) was only encoded by MAGs assigned to Desulfonatronum, Desulfurivibrio, and Desulfobulbaceae (GTDB taxonomy). The MAGs assigned to Desulfonatronum, Desulfonatronovibrio, and Desulfonatronospira, which are the genera that include haloalkaliphilic lithoautotrophic SRB also capable of thiosulfate/ sulfite disproportionation [7], encoded for a thiosulfate/ polysulfate reductase chain A ( $p h s A)$. Our MAGs affiliating with Desulfurivibrio, a genus known for thiosulfate/ polysulfide reduction and disproportionation, lacked the $p h s A$ gene. KEGG orthologs for the phs B and C subunits were not found in general. The phsA gene (but no sat/apr genes) was present also in putative species within the
Alpha- and Gammaproteobacteria and several taxonomic groups not usually associated with the sulfur cycle, such as the phyla Verrucomicrobia (Opitutae), DeinococcusThermus (Trueperaceae), Bacteroidetes (Bacteroidales), Actinobacteria (Egibacter, Nitriliruptoraceae, Nitriliruptorales), Ignavibacteria (Ignavibacteriales), and Spirochaetes (Spirochaetaceae, Spirochaetales). In line with the metagenomic evidence, the transcripts from phsA originated from a wide diversity of organisms, but the most abundant transcripts were assigned to the members of the Firmicutes (most closely affiliated with Salipaludibacillus and Syntrophomonadaceae) or the Deltaproteobacteria.

One putative archaeal species within the phylum "Candidatus Woesearchaeota" (DPANN superphylum) encoded for the catalytic B subunit of the dissimilatory sulfite reductase found previously in sulfite-respiring enteric bacteria [49] (asrB; Table 1). The location of $a s r B$ in the genome suggests an important role within the central metabolism of this organism, as it was encoded alongside an acetate kinase $(a c k A)$ and phosphate-acetyltransferase (pta), a pyruvate dehydrogenase, a NADH:ubiquinone oxidoreductase, a putative sulfhydrogenase subunit delta, a $\mathrm{Ni} / \mathrm{Fe}$ hydrogenase subunit alpha, and a hydrogenase formation chaperone (HypC/HypG/HupF family). "Ca. Woesearchaeota" was identified among the top 50 most abundant genera in the brine and sediments of Cock Soda Lake (Fig. 2), but no asrB transcripts were found in the metatranscriptome.

\section{Colorless SOB and purple sulfur bacteria strongly link cycling of sulfur to carbon and nitrogen fixation}

Besides Thioalkalivibrio, several potential novel autotrophic SOB species were detected within the Gammaproteobacteria 


\section{a}

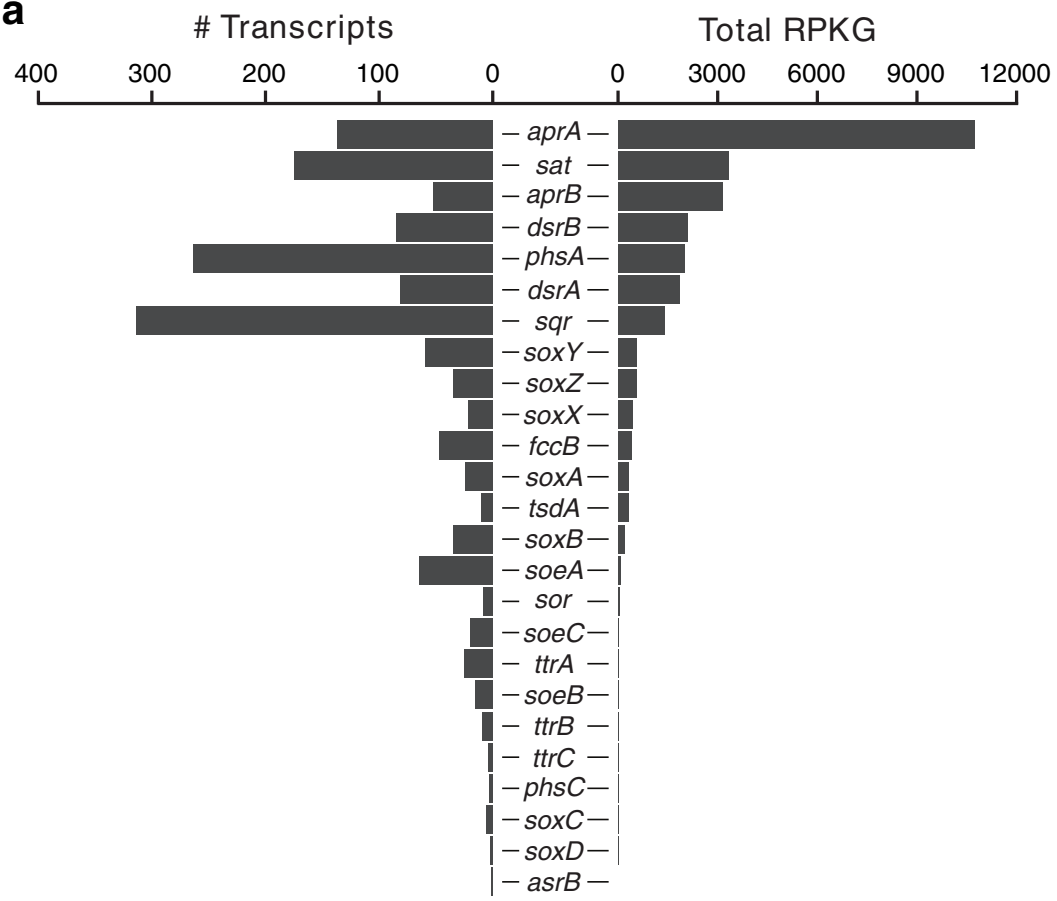

b
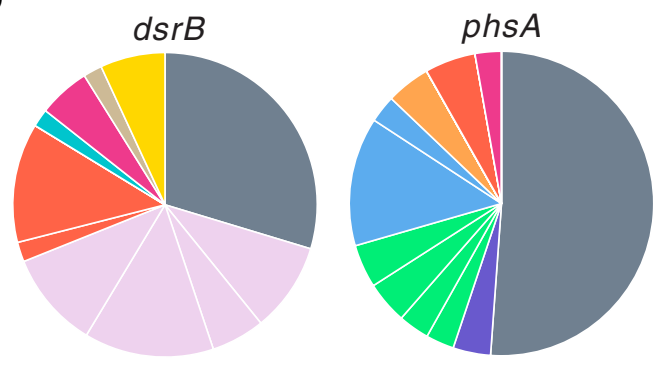

Desulfococcaceae bac. sp. 1

Syntrophobacteraceae bac. sp. 1

Desulfonatronospira sp. 4

Desulfonatronum sp. 2

Desulfonatronovibrio

Desulfonatronum

Desulfococcaceae

Salipaludibacillus

Desulfonatronospira

Syntrophomonadaceae

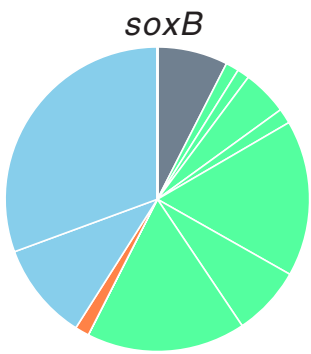

Thioalkalivibrio sp. 1

Thiohalocapsa

Thioalkalivibrio

remaining transcripts

$t s d A$

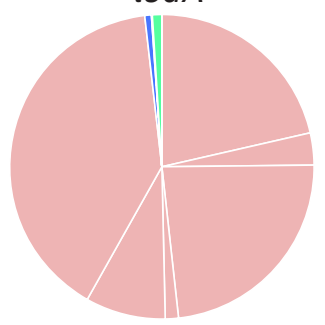

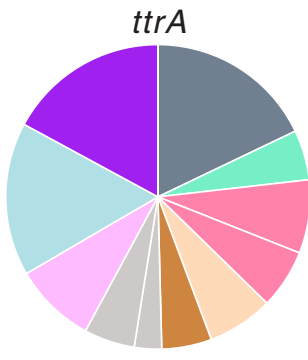

Marinospirillum

Nitrincola

Cecembia

Desulfobacteraceae bac sp. 2

Alkalilimnicola

Nitriliruptorales

Geopsychrobacteraceae

Alkaliphilus

Nitriliruptoraceae

Halomonas sp. 1

Tissierella

Fig. 5 (See legend on next page.) 
(See figure on previous page.)

Fig. 5 Abundance and taxonomic assignments of transcripts originating from sulfur cycle marker genes. a The number of unique transcripts (> $100 \mathrm{AA}$ ) and total abundance, expressed as reads per kilobase of sequence per gigabase of mapped reads (RPKG). RPKG was calculated for the complete contig on which each transcript was found and summed for each gene transcribed. $\mathbf{b}$ Taxonomic assignment of the top 10 most abundant transcripts of $d s r B$, phs $A$, soxB, tsdA, and ttrA. When a transcript was found to be $100 \%$ identical to a gene found on a MAG, the species assignment is given as a number

that encoded for the incomplete Sox-enzyme system without SoxCD (Fig. 4). In combination with a sulfide:quinone reductase (sqr) or a flavocytochrome c sulfide dehydrogenase $(f c c A B)$, a reversed dissimilatory sulfite reductase $(\operatorname{dsr} A B)$ and a sulfite-quinone oxidoreductase $(\operatorname{soe} A B C)$ can be used for the complete oxidation of $\mathrm{HS}^{-}$or other reduced sulfur compounds with formation of a zero-valent sulfur intermediate coupled to carbon fixation ( $p r k B, r b c L M)$. All MAGs encoded at least for a $\mathrm{cbb}_{3}$-type cytochrome $c$ oxidase, an additional $a_{3}$-type was encoded only by the species representatives from Halorhodospira, one unclassified Gammaproteobacterium and one member of Thioalkalivibrio. In none of the MAGs, the $f c c A$ gene (K17230) was found by GhostKOALA, but in most instances when a $f c c B$ gene was present (K17229), an adjacent gene encoding for cytochrome $c$ subunit was identified by BlastP.

All sequenced $s o x B$ transcripts were assigned to the members of the Proteobacteria. The most abundantly transcribed genes were assigned to the chemolithoautotrophic genus Thioalkalivibrio, secondly to purple sulfur bacteria of the genus Thiohalocapsa (Fig. 5b). The capacity for $N O_{x}$ reduction within the genus Thioalkalivibrio differed between the putative species, some encoded near-complete pathways for denitrification, and others encoded dissimilatory nitrate reductases (nap or nar) and others a partial ammonifying nitrite reductase $(n r f A$; Additional file 10: Dataset 4). The species representative MAG of Thiohalocapsa encoded for a full ammonifying nitrite reductase $(n r f A H)$, but again no nar or nap genes were present.

One species within the Thiohalomonadaceae (GTDB taxonomy) could not be assigned to a known genus and might affiliate with a novel, uncharacterized genus of chemolithoautotrophic SOB related to the genus thiodenitrifying Thiohalomonas [50] (previously within the family Ectothiorhodospiraceae; Table 1). Although no genes for denitrification were found, the capacity for nitrogen fixation (nif genes together with regulatory genes: $r n f$ genes, dra genes, and a toxin-antitoxin system; Additional file 10: Dataset 4) was encoded, which is unusual for a colorless SOB. The reconstructed MAGs from the purple sulfur bacteria (encoding for puf and bch genes) genera Thiohalocapsa and Halorhodospira also encoded the capacity for nitrogen fixation, which is a typical trait for this functional group [42]. The third group of detected purple sulfur bacteria consisted of two species within the family Chromatiaceae not affiliated with known genera. None of these
Chromatiaceae MAGs contained the soe genes, but sulfite oxidation could occur via an adenylylsulfate reductase $(\operatorname{apr} A B)$ and sulfate adenylyltransferase (sat). It should be noted that the other alternative enzyme for sulfite oxidation (sulfur oxygenase reductase (sor)) was only found in MAGs from the genus Thioalkalivibrio.

In addition, several more putative species within the Gamma- and Alphaproteobacteria encoded for a part of the Sox-system (soxB, soxXA and/or sox $Y Z$ ), in combination with either soeABC (Rubritepida, Geminicoccales, Alkalilimnicola), dsrB (Saccharospirillaceae), both soeABC and $\operatorname{ds} A B$ (Thiorhodovibrio, Sedimenticolaceae, and Gammaproteobacteria), or without the presence of other marker genes for dissimilatory sulfur oxidation (Methylophaga, Methylomicrobium, Thiothrichales, Rhizobiales, Geminicoccaceae, Aquisalimonadaceae, and Pseudomonadales). This can indicate either a partial acquisition or a partial loss of the whole sulfur-oxidizing gene repertoire, or be the result of existing gaps in the reconstruction of the MAGs. Some of the MAGs assigned to Pseudomonadales and Sedimenticolaceae also encoded near-complete pathways for denitrification (Additional file 10: Dataset 4).

\section{Photoheterotrophic SOB encoding soxCD}

A full set of Sox-enzymes (including SoxCD), indicative of the potential for full thiosulfate oxidation to $\mathrm{SO}_{4}{ }^{2-}$ without the formation of intermediary zero-valent sulfur, was encoded by the members of the genera Natronohydrobacter and Rhodobaca and by one species representative of an unknown genus within the family Rhodobacteraceae (class Alphaproteobacteria; Table 1). One MAG from the Rhodobacteraceae family encoded for a polysulfide/thiosulfate reductase ( $p s r A / p h s A$ gene). All other MAGs including from the genera Roseinatronobacter and Roseovarius encoded just a partial set of Sox-enzyme, probably because the MAGs were not complete. The absence of RuBisCo and the presence of genes for anoxygenic photosynthesis (puf and bch genes; Additional file 10: Dataset 4) in these MAGs suggest a photoheterotrophic lifestyle, which is consistent with the genomes obtained from cultured isolates [51]. These organisms might obtain additional energy from the oxidation of carbon monoxide as most MAGs encoded for an aerobic CODH (coxL, coxM, coxS). All MAGs encoded for two types of cytochrome $c$ oxidases, with the exception of the putative species within Roseinatronobacter that encoded only for an $\mathrm{aa}_{3}$-type cytochrome $c$ oxidase. 
One species that affiliated with the Dehalococcoidia (phylum Chloroflexi) and four species of Gemmatimonadetes had sox $C D$ genes but did not encode for other Soxenzymes, and it is not clear what the role of the SoxCD might be in this case. At least in the well-established cases of the Sox system functioning in the proteobacterial SOB, SoxCD is never found alone. Three Gemmatimonadetes species were likely phototrophic (puf and $b c h$ genes) and encoded the capacity for dissimilatory nitrate reduction (napAB and $n r f A H$ ) to ammonia (Additional file 10: Dataset 4). One putative species had the additional potential capability for autotrophic carbon fixation (phosphoribulokinase, prkB; RubisCo type I, $r b c L M$; Table 1; Additional file 11: Figure S3) encoded in the genome. The presence of a putative aa3-type cytochrome c oxidase ( $\operatorname{cox} A B C D)$ further suggests an aerobic type of metabolism for this organism (Additional file 10: Dataset 4). Several MAGs from putative photoheterotrophic SOB (Rhodobaca, Rhodobacteraceae, Roseinatronobacter) and those assigned to the Dehalococcoidia encoded the capability for dissimilatory nitrate reduction to nitrite (narGH), but not for dissimilatory nitrite reduction to ammonia (DNRA) or further denitrification (Additional file 10: Dataset 4).

\section{Thiosulfate dehydrogenase-encoding heterotrophs}

Four groups within the Gammaproteobacteria (Thioalkalivibrio, Pseudomonas, Marinospirillum, Halomonas), one within the Bacteroidetes (Cecembia), and one within the Chlamydiae (Waddliaceae) encoded for a thiosulfate dehydrogenase ( $t s d A$; Fig. 4). Only in the gammaproteobacterial MAGs we identified adjacent to $t s d A$ a gene for a cytochrome $c 4$ (BlastP) that can function as an immediate electron acceptor for the two-electron oxidation of $\mathrm{S}_{2} \mathrm{O}_{3}{ }^{2-}$ to $\mathrm{S}_{4} \mathrm{O}_{6}{ }^{2}$. For several gammaproteobacterial heterotrophs, including haloalkaliphilic Halomonas species, thiosulfate oxidation is suggested to be used as an additional energy source to organotrophic growth and the produced $\mathrm{S}_{4} \mathrm{O}_{6}{ }^{2-}$ can chemically oxidize $\mathrm{HS}^{-}$[26]. All tsdA-encoding MAGs had the potential for aerobic respiration and encoded a $\mathrm{cbb}_{3}$-type terminal oxidase. The MAGs assigned to Cecembia, Halomonas, and Pseudomonas encoded for an additional $a_{3}$-type. One putative Halomonas species detected here also encoded for a near-complete denitrification pathway (narGH, nirS, norBC, nosZ; Additional file 10: Dataset 4). The most actively transcribed $t s d A$ genes in the top $2-\mathrm{cm}$ layer of sediments could not be traced back to any of the reconstructed MAGs, but affiliated with c-type cytochromes from Nitrincola sp. A-D6 (80-92\% AA identity; Fig. 5b). The remaining two transcripts were from the members of the genera Marinospirillum (Gammaproteobacteria) and Cecembia (Bacteroidetes). Halomonas might be more abundant and active in deeper sediment layers, as OTUs assigned to this genus were the most abundant in the 16S rRNA gene amplicons recovered from below 10 $\mathrm{cm}$ of depth (relative abundance $\sim 15 \%, 21 \%$, and $23 \%$ in the 10-15-cm, 15-20-cm, and 20-25-cm layers of sediment, respectively; Fig. 2).

The potential for thiosulfate oxidation using a thiosulfate:quinone oxidoreductase (DoxAD) as done by some acidophilic SOB and sulfur-oxidizing archaea [23] was also found in three species of Bacteroidetes (Lishizhenia, Cryomorphaceae, and Flavobacteriales; Fig. 4, Table 1). Transcripts of the doxAD genes were not found (Fig. 5), although genes for DoxX family proteins, which besides DoxD include mostly uncharacterized proteins wrongly annotated by GhostKOALA as DoxD (K16937), were abundantly transcribed.

\section{Widespread and actively transcribed putative tetrathionate reductase genes}

A variety of different phylogenetic and functional groups encoded for a complete or partial tetrathionate reductase (ttrABC; Fig. 4). Complete tetrathionate reductases were encoded by three putative species within the Gammaproteobacteria (Alkalilimnicola, Table 1; Halomonas; and Ectothiorodospiraceae), one species within the Bacteroidetes, six species within the Actinobacteria (Nitriliruptoraceae and Nitriliruptorales), and three species within the Deltaproteobacteria (Desulfobacteraceae/Desulfococcaceae, Desulfosarcinaceae, and Geopsychrobacteraceae, Table 1). In the MAGs assigned to the three putative gammaproteobacterial species and to the Desulfococcaceae, an anoxia-responsive global transcriptional regulator (fur, CPR/FNR family) was encoded, which was found to be essential for transcription of the $t$ tr genes in Salmonella typhimurium [52]. In the MAGs affiliating with Alkalilimnicola and Ectothiorhodospiraceae, a ttrS gene was found near the $\operatorname{tr} A B C$ genes, which is part of a two-component regulatory system for tetrathionate respiration. Although overall ttrA transcription was low compared to the other marker genes (Fig. 5a), transcripts were assigned to a variety of taxonomic groups within the Deltaproteobacteria, Gammaproteobacteria, and Actinobacteria also detected in the metagenomes, as well as to the Firmicutes (Alkaliphilus and Tissierella).

\section{Discussion}

By high-throughput sequencing, we confirmed the presence and transcriptional activity of many cultured groups of prokaryotes and potential novel groups that dissimilate inorganic sulfur compounds in the moderately hypersaline $\left(55 \mathrm{~g} \mathrm{~L}^{-1}\right.$ total salt) Cock Soda Lake, confirming previous studies that a complete sulfur cycle between $\mathrm{SO}_{4}{ }^{2-}$ and $\mathrm{HS}^{-}$can occur at such a salinity level in soda lakes [8]. Most of the nucleic acids were recovered in the largely anoxic top few centimeters of sediments, which strongly suggests that the sediment-brine 
interface and the partially oxidized sediment surface layer were a hotspot for microbial growth and activity. In this top 2-cm layer of the sediments, heterotrophs, lithotrophic SRB, purple sulfur bacteria, and chemolithoautotrophic SOB were transcriptionally active and had the potential to tightly link the biogeochemical cycles of carbon, nitrogen, and sulfur. Many members of the latter three functional groups had the ability to fix nitrogen in addition to inorganic carbon. The majority of the deltaproteobacterial SRB encoded the capacity for DNRA (nrfAH), although mostly decoupled from dissimilatory nitrate reduction to nitrite. The possibility for growth by sulfide oxidation coupled to dissimilatory nitrate reduction to ammonia by the members of Desulfonatronum, Desulfurivibrio, and a novel genus within the Desulfobulbaceae, for which we recovered MAGs encoding additionally for napA, warrants further investigation, as this process was recently shown for Desulfurivibrio alkaliphilus [16]. Also in some SOB MAGs assigned to Thioalkalivibrio and a MAG recovered from Thiohalocapsa, dissimilatory nitrite reductases were found (nirKS and nrfAH, respectively), but not together with nitrate reductases in the same genome. Marker genes for complete denitrification were found mostly in gammaproteobacterial MAGs, including putative chemolithoautotrophic and lithoheterotrophic SOB. Putative heterotrophic and denitrifying $\mathrm{SOB}$ from the genus Halomonas seem to be relatively more important deeper in the sediments. There, the type and amount of organic substrates as well as the extreme low redox potential are perhaps less favorable for other heterotrophs, such as the members of the ML635J-40 aquatic group (Bacteroidetes) that are dominant in the top layer of sediments and presumably contribute to the degradation of dead phototrophic biomass [53].

High amounts of methane were detected in the brine that exceeded the concentrations measured in the sediment. It is not clear if this methane was produced by methanogens in the anoxic sediment layers and later trapped in the brine, or if aerobic methane production in the brine itself occurred. We also obtained one MAG of a putative methanotroph from the $0-5-\mathrm{cm}$ sediment layer assigned to the genus Methylomicrobium, from which halo (alkali) philic methanotrophs have been previously isolated [54]. On the other hand, we could not detect free $\mathrm{HS}^{-}$in the brine or down to $25-\mathrm{cm}$ sediment depth. This suggests $\mathrm{HS}^{-}$is rapidly turned over by SOB in the top layers, chemically oxidized, or bound as $\mathrm{FeS}$ in the deeper layers. We showed that the intermediate $\mathrm{S}_{2} \mathrm{O}_{3}{ }^{2-}$ is rapidly oxidized by $\mathrm{SOB}$ from the sediment top layer under oxic conditions, but found that when the top 2-cm sediment was amended with millimolar concentrations of $\mathrm{S}_{2} \mathrm{O}_{3}{ }^{2-}$, oxidation was partially inhibited under light conditions. Since this phenomenon did not occur when the sediments were amended with micromolar concentrations of $\mathrm{S}_{2} \mathrm{O}_{3}{ }^{2-}$, we infer that the lightinhibited $\mathrm{SOB}$ are those using enzymes with low $\mathrm{S}_{2} \mathrm{O}_{3}{ }^{2-}$ affinity. The lower rates of thiosulfate conversion obtained for the $2-4-\mathrm{cm}$ sediment layer is presumably the result of an overall decline in microbial biomass with sediment depth.

Also, the reductive part of the sulfur cycle is likely primed to the top $2 \mathrm{~cm}$ of sediments where most of the DNA and RNA were recovered. A previous study found a steep drop in the sulfate reduction rates below $2 \mathrm{~cm}$ of sediment depth determined in situ for Cock Soda Lake [31], which is also in agreement with our sulfate concentration profiles and the relatively higher 16S rRNA gene transcripts assigned to SRB found in the 0-2-cm layer compared to the 2-4-cm layer. Further, we found the widespread presence and transcription of a subunit of putative thiosulfate/polysulfide reductase homologs in the top layer of sediments, including with affiliation to some taxonomic groups not previously associated with the sulfur cycle. This did not coincide with the depletion of $\mathrm{S}_{2} \mathrm{O}_{3}{ }^{2-}$ under anoxic conditions, as we were able to measure micromolar concentrations of $\mathrm{S}_{2} \mathrm{O}_{3}{ }^{2-}$ in the pore brine of the top 4-cm sediment layer. This could indicate that the substrates for these reductases are mostly $\mathrm{S}_{n}{ }^{2-}$, which are stable compounds under anoxic, haloalkaline conditions and were previously shown to be the preferred substrate at least for isolated SRB [55]. On the other hand, we cannot exclude that the detection of the partially oxidized sulfur intermediates $\mathrm{S}_{2} \mathrm{O}_{3}{ }^{2-}$ and $\mathrm{SO}_{3}{ }^{-}$might have been an artifact from the pore water extraction procedure. A somewhat surprising finding was that despite the chemical instability and reactivity of $\mathrm{S}_{4} \mathrm{O}_{6}{ }^{2-}$ with $\mathrm{HS}^{-}$at high $\mathrm{pH}$ [26], full tetrathionate reductases were transcribed by several anaerobic and facultative anaerobic Bacteria. This could mean that the sulfur intermediate $\mathrm{S}_{4} \mathrm{O}_{6}{ }^{2-}$ is biologically available as an electron acceptor at an alkaline $\mathrm{pH}$, perhaps in this case because $\mathrm{HS}^{-}$is rapidly consumed by other processes.

Compared to the MAGs reconstructed previously from sediments of Kulunda Steppe soda lakes [35], a total of 12 MAGs were recovered in this study from 3 extra phyla, namely the Oligoflexia (Bdellovibrionota), "Candidatus Delongbacteria," and from the "Candidatus Lokiarchaeota" within the superphylum Asgardarchaeota, an archaeal group from which the eukaryotes are envisioned to have emerged [56]. Some of the most transcriptionally active organisms in the dissimilatory sulfur cycle were not previously recognized to be haloalkaliphiles [7], such as purple sulfur bacteria from the genus Thiohalocapsa and a new species of SRB from the family (Desulfococcaceae/Desulfobacteraceae). Additionally, several new MAGs were obtained with some unusual metabolic potential for specific taxonomic groups. First, we 
found a MAG from a member of the phylum Gemmatimonadetes with the capacity for photoautotrophy, while the single characterized phototroph from this phylum is a photoheterotroph $[57,58]$. Second, we found the capacity for nitrogen fixation in a colorless SOB from the family Thiohalomonadaceae, which is a remarkable trait for this functional group. To our knowledge, only few free-living colorless SOB from the genus Thiothrix [59] and 1 marine, chemoautrophic mollusk symbiont [60] are known to perform nitrogen fixation. Third, we found a MAG from the "Ca. Woesearchaeota" with an encoded subunit of a sulfite reductase $(a s r B)$, which is peculiar as the phylogenetic distribution of this enzyme is thought to be restricted to the domain Bacteria [61]. The genomic setting of asrB exhibited strong similarity with that in the genome of the sulfur-reducing hyperthermophilic, heterotrophic archaeon Pyrococcus furiosus [62] and should deserve further attention. Previously, an anaerobic heterotrophic lifestyle and a symbiotic association with methanogens have been suggested for most members of the "Ca. Woesearchaeota" [63]. Although this study included a wide range of oxic and anoxic environments globally, it did not yet include the most recent 23 MAGs of haloalkaliphiles $([40,45])$ that seem to occur abundantly both in soda lake brines and sediments. We identified here at least 1 species of the "Candidatus Woesearchaeota" that might be capable to reduce sulfur compounds.

In general, more detailed genome analysis and physiological assays are needed to better understand the genetic context and the function of hypothetical proteins, but these are beyond the scope of this paper. In addition, metagenomes are a snapshot in space and time, and metatranscriptomes even more so. Since we were only able to obtain one metatranscriptome from the sediment surface layer, many open questions remain. Not only would it be preferable to compare the transcription under light versus dark conditions, our failure to obtain sufficient nucleic acids from below 5 -cm sediment depth is an invitation to investigate the sediment top layer at a finer scale in future studies and to collect far larger volumes of sediment from the deeper layers for nucleic acid extraction.

\section{Conclusion}

We uncovered the presence of new haloalkaliphilic prokaryotes that still evade culturing efforts, some with unusual metabolic potential. A new genus of colorless SOB from the family Thiohalomonadaceae might be capable of fixing nitrogen, which is a rare trait for this functional group. We obtained MAGs from a new species within the "Ca. Woesearchaeota" with the potential for elemental sulfur/sulfite reduction. Although its role in the sulfur cycle is less certain, we found one new species within the recently characterized phylum Gemmatimonadetes with genes indicating the capacity for autotrophy and aerobic anoxygenic phototrophic growth. We found that the sediment microbial community oxidized $\mathrm{S}_{2} \mathrm{O}_{3}{ }^{2-}$ rapidly in the presence of oxygen, but that oxidation was partially inhibited by light. Although putative thiosulfate/polysulfide reductases were highly transcribed by a great variety of taxonomic groups, including some not usually associated with inorganic sulfur compound cycling, we could still measure $\mathrm{S}_{2} \mathrm{O}_{3}{ }^{2-}$ in the sediment pore water. Finally, despite its reactivity, we found that $\mathrm{S}_{4} \mathrm{O}_{6}{ }^{2}$ ${ }^{-}$, an intermediate of sulfur oxidation unstable at soda lake conditions, could potentially also be used as an electron acceptor by many functional groups of the soda lake prokaryotic community.

\section{Methods}

\section{Sampling, preservation and in situ measurements}

During a fieldwork survey in July 2016, samples were taken in the littoral zone of Cock Soda Lake (Kulunda Steppe, southwestern Siberia, Altai, Russia). On site, the total salinity in the brine was determined with a refractometer. Brine alkalinity was determined by titrating first sodium carbonate to bicarbonate in the presence of phenolphthaline $(\mathrm{pH} \sim 8)$, then the total bicarbonate (i.e., originating from carbonate + the original pool) to carbonic acid with $1 \mathrm{M} \mathrm{HCl}$ in the presence of methyl orange ( $\mathrm{pH} \sim 4.5$ ). One 20 -cm-long sediment core was processed in the field into 5 -cm-thick slices for the determination in the laboratory of acid-volatile sulfide content $(\mathrm{FeS})$, free sulfides, and methane in the pore water as described by [64]. Additional small samples $(\sim 2$ $\mathrm{mL}$ ) from each layer of this column were well mixed, later flash-frozen in the laboratory, and stored at $-20^{\circ} \mathrm{C}$ for DNA isolation. In order to target primarily the planktonic prokaryote communities, brine samples were filtered through $5-\mu \mathrm{m}$ pore-sized syringe filters to remove phytoplankton cells and large particles. The filtrate was mixed with an equal portion of sterile DMSO $(20 \% v / v)$-EDTA $(0.25 \mathrm{M})$ salt-saturated buffer (DESS [65]) to preserve the microbial communities upon transport to the laboratory. Three sediment cores of $12 \mathrm{~cm}$ length $(\varnothing 6 \mathrm{~cm})$ were cut into 2-cm-thick layers and well mixed. Smaller subsamples ( $3 \mathrm{~mL} \sim 6 \mathrm{~g}$ wet weight) from each layer were stored with $12 \mathrm{~mL}$ "LifeGuard Soil Preservation Solution" (MO BIO) directly in bead beating tubes to preserve the DNA and RNA upon transport to the laboratory. The remaining sediments from each layer were combined, flash-frozen with liquid nitrogen after transport to the laboratory, and stored at $-80^{\circ} \mathrm{C}$ both for DNA isolation and determination of general sediment characteristics.

\section{General sediment characteristics}

Sediment samples were freeze-dried, and dry weight was determined using a four-decimal scale. After treatment 
with hydrogen peroxide and hydrochloric acid, standard grain size analysis was applied using a set of mesh sieves for the fraction $>125 \mu \mathrm{m}$ and a sedigraph (Sedigraph III Plus, Micrometrics) for the fraction $<125 \mu \mathrm{m}$. Total carbon content was determined by dry combustion with an elemental analyzer (Elementar Vario El Cube, Germany). Inorganic carbon was determined based on gravimetric loss of carbonates as carbon dioxide in the presence of excess hydrochloric acid [66]. After microwave-assisted (PAAR Physica multiwave) digestion in Aqua regia, total sulfur, phosphorus, manganese, and iron concentrations in the sediment were measured using an ICP-OES (Perkin Elmer Optima 8000 crossflow).

\section{Biogeochemical profiling}

Three intact replicate cores were transported back to the laboratory for chemical analyses of the pore water, potential activity measurements, and microsensor measurements. Before measuring, the columns were kept for 1 week at constant temperature $\left(20^{\circ} \mathrm{C}\right)$ under a $16: 8$-h day/night light regime to allow displaced pore water ions to equilibrate. Detailed oxygen and redox (oxidation-reduction potential against a silver/silver-chloride reference electrode) profiles of the top layer sediment were measured at three different spots of each core, manually maneuvering microsensors with a $25-\mu \mathrm{m}$ glass tip (Unisense, Aarhus, Denmark) from the top of the sediment downwards. $\mathrm{pH}$ profiles were measured once for two columns. The electrodes were connected to a "Microsensor Multimeter" (Software Unisense Microsensor), calibrated in the appropriate $\mathrm{pH}$ range and handled according to the manufacturer's instructions.

After the microsensor measurements, the pore water from one sediment column was extracted from $30-\mathrm{cm}^{3}$ subsamples of the top $0-2-\mathrm{cm}$ and $2-4-\mathrm{cm}$ layers by centrifugation $\left(1 \mathrm{~h}\right.$ at $19000 \times g$ and $\left.4{ }^{\circ} \mathrm{C}\right)$. After $0.2-\mu \mathrm{m}$ filtration, half of the pore water was fixed with zinc acetate $(5 \% \mathrm{w} / v$ final concentration, to trap free sulfides that might damage the column) for thiosulfate, sulfate, nitrate and chloride determination with an ion chromatograph (IC). The other half was used for thiosulfate and sulfite determination. The samples were stored at $80^{\circ} \mathrm{C}$ until analysis.

A second sediment column was further used for activity measurements. The top $0-2-\mathrm{cm}$ and $2-4-\mathrm{cm}$ layers of the sediment were mixed well, and $1-\mathrm{mL}$ subsamples were added to sterile $50-\mathrm{mL}$ flasks with a sterile cutoff syringe. To measure thiosulfate $\left(\mathrm{S}_{2} \mathrm{O}_{3}{ }^{2-}\right)$ consumption under oxic conditions, $14 \mathrm{~mL}$ of $0.2-\mu \mathrm{m}$-filtered natural brine was added and bottles were closed with cotton stoppers. The live sediment slurries were placed on a shaker and allowed to acclimatize overnight either under white light (15 W "Edmund Bühler TH30 Incubator Hood," measured PAR photon flux between 18 and
$33 \mu \mathrm{mol} \mathrm{m}^{-2} \mathrm{~s}^{-2}$ with "Li-Cor Light Meter" model LI250 ) or in the dark. Dead controls were established by autoclaving the sediments three times at $120^{\circ} \mathrm{C}$ for 20 min. To determine the consumption in the micromolar range, duplicate bottles for each sediment layer and pretreatment were spiked with final concentrations of $200 \mu \mathrm{M} \mathrm{S}_{2} \mathrm{O}_{3}{ }^{2-}$. All bottles were sampled immediately after spiking $\left(t_{0}\right)$ and after 8,24 , and $48 \mathrm{~h}$ of incubation. To determine thiosulfate consumption in the millimolar range, the thiosulfate-exposed slurries were spiked a second time to a final concentration of $3 \mathrm{mM} \mathrm{S}_{2} \mathrm{O}_{3}{ }^{2-}$ after replenishing the liquid phase with sterile brine to $19 \mathrm{~mL}$ and overnight acclimatization. The incubations were sampled immediately after the second spike $\left(t_{0}\right)$ and after $3,6,12,24$, and $48 \mathrm{~h}$ of incubation. Before sampling, all bottles were stirred thoroughly by hand after which large particles could settle briefly. All samples were taken from the liquid phase and filtered through a $0.22-\mu \mathrm{m}$ PES membrane. Samples for the UPLC (micromolar range) were flash-frozen with liquid nitrogen and stored at $-80^{\circ} \mathrm{C}$. Triplicate samples for the IC (millimolar range) were fixed in excess zinc acetate $(1.5 \% \mathrm{w} / \mathrm{v}$ final concentration) and stored at $-80^{\circ} \mathrm{C}$.

\section{Sulfur compound and methane analyses}

Acid-volatile sulfide (FeS) and free sulfides were determined with the methylene blue method according to [55]. Methane concentrations were measured using gas chromatography according to [64]. Thiosulfate and sulfite concentrations were determined by ultraperformance liquid chromatography (UPLC) after monobromobimane (MBB) derivatization using a method from [67], but modified for alkaline conditions. Thiosulfate and sulfite standards were prepared in the sulfatefree, degassed artificial soda medium. Samples were thawed, sonicated for $10 \mathrm{~min}$ in an ultrasound bath, and transferred to dark glass vials. To lower the $\mathrm{pH}$ to 8 and allow adequate reaction of thiosulfate with $\mathrm{MBB}, 50 \mu \mathrm{L}$ of concentrated methanesulfonic acid (MSA, $1.5 \mathrm{M})$ was added to $200-\mu \mathrm{L}$ samples and standards. After letting the preparations briefly degas, samples and standards were derivatized in the dark with a freshly prepared derivation mixture $(25 \mu \mathrm{L} 10 \mathrm{mg} / \mathrm{mL} \mathrm{MBB}$ in acetonitrile and $25 \mu \mathrm{L} 500 \mathrm{mM}$ HEPES-50 mM EDTA buffer $\mathrm{pH} 8$ ) for $30 \mathrm{~min}$ at room temperature. The reaction was stopped by adding $50 \mu \mathrm{L}$ concentrated MSA. Derivatized samples and standards were analyzed on a "Waters Aquity" UPLC (Aquity UPLC BEH C8 $1.7 \mu \mathrm{m}, 2.1 \times 50$ $\mathrm{mm}$ column) with fluorescence detection (excitation $380 \mathrm{~nm}$, emission $480 \mathrm{~nm}$ ). Sulfate and thiosulfate concentrations in diluted samples (total 60x) were determined on a "Metrohm" ion chromatograph using electronically background conductivity suppression and 
conductivity detection. Fresh standards were prepared daily.

\section{Nucleic acid extraction and processing}

Simultaneous extraction of DNA and RNA from "Lifeguard"-preserved samples (triplicates) was performed with the "RNA PowerSoil ${ }^{\circ}$ Total RNA Isolation Kit" (MO BIO). The DNA in the total RNA was digested with DNase I ("Turbo DNA-free kit," Ambion), and no further residual 16S rRNA gene contamination could be detected after a 30-cycle PCR (Additional file 12: Figure S7). For amplicon sequencing of the 16S rRNA gene transcripts, DNA-free RNA was transcribed into single-stranded cDNA using random hexamer primers ("SuperScript First Strand synthesis kit," Invitrogen). Additional DNA was isolated from flash-frozen sediment samples and the DESS-preserved brine sample using the "PowerSoil DNA isolation kit" (MO BIO) and further cleaned with a "Genomic DNA Clean \& Concentrator kit" (Zymo). The brine/DESS mixture was first filtered onto $0.2-\mu \mathrm{m}$ pore-sized sterile membrane filters. Sediment samples and filter pieces were first incubated at $65^{\circ} \mathrm{C}$ under light shaking in Solution S1 before proceeding to further DNA extraction according to the manufacturer's instructions. All nucleic acids were checked on agarose gels and quantified with "Qubit" standard assays (Invitrogen).

\section{S rRNA gene and transcript amplicon sequencing and analysis}

Before amplicon sequencing, DNA and cDNA solutions were standardized to concentrations to 1,5 , or $20 \mathrm{ng} / \mu \mathrm{L}$. At the sequencing center (MR DNA), 16S rRNA gene and transcript fragments were amplified using the 515F$\mathrm{Y} / 926 \mathrm{R}$ primer set (targeting the $\mathrm{V} 3-\mathrm{V} 4$ region) as described before [68]. The individual samples were barcoded, and the mixtures were sequenced on a "Illumina MiSeq" platform. The $2 \times 300$ bp paired-end amplicon sequence reads were merged and re-orientated, and the reads shorter than $200 \mathrm{~b}$, primers, and adapters were removed. Reads $\geq 150$ b were further quality trimmed using Sickle (default parameters; [69]), and the dataset was further processed with the automated NGS analysis pipeline of the SILVA rRNA gene database project (SILVAngs 1.3, db v132) [70]. The resulting OTUs (clustered at $98 \%$ identity) and assigned taxonomy ( $\geq 93 \%$ identity BLAST) were further analyzed with the package ampvis2 in " $R$ " [71].

\section{Metagenomes and metatranscriptome sequencing}

The DNA mixtures isolated from the brine $(\sim 3 \mu \mathrm{g})$, the top $0-2$-cm sediment layer $(\sim 4$ and $6 \mu \mathrm{g})$, and the top $0-5$-cm layer $(\sim 6 \mu \mathrm{g})$ were used for direct metagenomics sequencing. At the sequencing center (Beijing Genomics Institute), the quality and integrity of the
DNA were again verified before preparing short-insert (350 bp) libraries. The DNA was fragmented (Covaris), end-repaired (End Repair Mix), and purified ("QIAquick PCR Purification kit," Qiagen). Adapters were ligated at 3 ' adenylated ends of the DNA fragments, and adapterligated DNA fragments were enriched by several rounds of PCR amplification.

Only from the $0-2-\mathrm{cm}$ top layer enough RNA $(\sim 7 \mu \mathrm{g})$ was isolated for direct metatranscriptome sequencing. The DNA-free RNA was pooled from triplicate extractions after checking its integrity on an agarose gel (Additional file 12: Figure S7). At the sequencing center (BGI), the total RNA concentration, the RNA integrity number (RIN), the $23 \mathrm{~S}$ to $16 \mathrm{~S}$ ratios, and the fragment size were verified with a "Agilent 2100 Bioanalyzer" (Agilent RNA 6000 Nano Kit). The purity of the samples was tested using "NanoDrop ${ }^{\text {tus" }}$ before preparing the prokaryotic strand-specific libraries (Illumina Truseq). A second DNase I digestion was performed, and rRNA was depleted (Ribo-Zero ${ }^{\mathrm{T}}$ Magnetic Kit). After fragmentation, the first-strand cDNA was generated using random primers, and second-strand cDNA was synthesized and end-repaired. Adapters were ligated at 3' adenylated ends of the cDNA fragments.

The quantity and quality of the DNA and cDNA libraries were checked again on the "Agilent 2100 Bioanalyzer" and with RT-qPCR using "TaqMan Probes" before preparing flow cells. Libraries were paired-end sequenced $(2 \times$ $150 \mathrm{bp}$ ) on a "Illumina HiSeq4000" platform, and lowquality reads were removed (40\% of bases with $Q<20$ or $50 \%$ adapter).

\section{Metagenomic analysis}

Metagenomic reads were quality and length (>21 b) trimmed with Sickle [69] and Illumina adaptor/vectors and primers removed with BBDuk [72]. Trimmed reads were assembled into $\geq 1 \mathrm{~kb}$ contigs using MEGAHIT (version v1.0.3-6-gc3983f9 [73], --k-min 21, --k-max 121, --kstep 10). Additional metrics on the raw sequence data and assembled contigs are given in Additional file 3: Table S3. Open reading frames were predicted with Prodigal [74], tRNAs were predicted with tRNAscan-SE [75], and rRNAs were predicted with rna_hmm3. The assembled 16S rRNA gene sequences were annotated using the SILVA SSU database v132 ( $e$ value $\geq 1 \mathrm{e}-5$ [70]). The predicted protein sequences were annotated against the KEGG database with GhostKOALA [76].

Differential coverage binning of $\geq 2.5$ - $k b$ contigs was done with Metabat2 (version 2.12.1 [77]; default settings). To improve the binning process, coverage was not only calculated for the metagenomics read sets sequenced for this study [46], but also for previously obtained metagenomes from Kulunda Steppe soda lakes [34, 35, 78-86] by mapping all read sets on the assembled contigs with BBmap (version v36.x [87]). Post- 
binning analysis on the resulting 2062 bins was done with Anvi'o [88] as described before [35], only without manually removing virus-related genes from the bins. Overall, 1032 novel metagenome-assembled genomes (MAGS) were obtained that were of reasonable quality ( $\geq 50 \%$ CheckM-completeness and $<10 \%$ contamination) and/or were assigned to the candidate phyla radiation (CPR; Additional file 4: Dataset 1) [40]. Taxonomic assignment of the individual MAGs was based on GTDB taxonomy [89] which uses concatenated protein phylogeny. The environmental abundance of the MAGs was estimated by calculating RPKG (= mapped reads per $\mathrm{kb}$ MAG sequence per Gb mapped reads) after mapping (> $95 \%$ similarity of $>25$ bases) 10 million randomly generated read subsamples from all available Cock Soda Lake metagenomes, including 2 metagenomes previously obtained from the top $10-\mathrm{cm}$ sediment layer sampled in 2010 and 2011 [35, 84, 85].

Among the newly obtained MAGs [40] and 401 MAGs previously obtained from Cock Soda Lake [35, 45], around 400 MAGs encoded marker genes (K number assignments) for dissimilatory sulfur compound transformations. We further simplified the MAG dataset based on assigned taxonomy and average nucleotide identity (ANI; [90]), retaining 263 MAGs as the best species representative (highest CheckM-completeness) for each putative sulfur-cycling group. When the GTDB taxonomy of these species representatives could not be assigned down to the genus level, the relatedness of these species representatives was further assessed based on the phylogeny of 16 ribosomal proteins as described previously [35] (Additional file 6: Dataset 2). For all the species representatives, more detailed comparative sequence and phylogenetic analyses were performed with reference protein sequences from the eggNOG database [91] to confirm the KEGG annotation, including characterized reference proteins for the following S-cycling genes: $\operatorname{doxD}$ [23], tsdA [24], ttrA [52], soxB [19], and $d s r B$ [92]. For $\operatorname{dox} D$ and soxB, initial trees were calculated to discriminate the bonafide $\operatorname{doxD}$ and soxB sequences from $\operatorname{dox} X$ family proteins and 5 '-nucleotidases, respectively. For $p h s A$, reference protein sequences were retrieved from the NCBI protein database. The final phylogenetic trees are available through figshare [93]. Additionally, marker genes for central metabolic pathways and key environmental element transformations were identified based on $\mathrm{K}$ number assignments. A phylogenetic tree including the AA sequence for the large subunit of RubisCo of one Gemmatimonadetes MAG was constructed according to [35].

\section{Metatranscriptome analysis}

Metatranscriptomic reads were quality and length trimmed, and contaminants and vectors were removed with BBDuk [72]. The reads were mapped against the assembled $\geq 1 \mathrm{~kb}$ metagenomics contigs (originating from the same sample) with Bowtie2 [94] for strand-specific libraries (--nofw) using the "very sensitive" mode and allowing one mismatch in the seed alignment. Since this resulted in a low poor alignment rate, we opted for de novo assembly of transcripts. The rRNA (LSU, SSU, $5 \mathrm{~S}$ rRNA, and 5.8S rRNA) encoded on both read mates were first removed with SortMeRNA [95]. Other noncoding RNA (ncRNA) of interest (including tRNA, mtRNA, CRISPRs, OLE RNA) on the trimmed metatranscriptomic reads were identified using Infernal against the Rfam database (version 14.0; [96]) but were not removed from the read sets. Assembly was performed with MEGAHIT (v1.1.2 [73], --k-min 21, --k-max 121, --kstep 10) retaining contigs $\geq 200 \mathrm{~b}$. Additional metrics on the raw metatranscriptome sequence data and assembled transcripts are given in Additional file 3: Table S4. Open reading frames on the resulting cDNA transcripts were predicted with Prodigal; predicted proteins were annotated with GhostKOALA [76] and scanned for S-cycling marker genes based on $\mathrm{K}$ number assignments. The KEGG annotations were confirmed by including the transcripts in the single gene trees (see the previous paragraph). Transcripts $>100$ amino acids that were contained already in longer transcripts were dereplicated with dedupe.sh [97] (100\% identity, $k=11)$. Relative abundances of the de-replicated S-gene transcripts $>100$ amino acids were estimated by calculating RPKG for the full contigs after mapping (> 95\% similarity of $>25$ bases) $25 \%$ of the metatranscriptomic forward reads used for assembly. Where possible, S-gene transcripts were linked to the obtained MAGs and inferred species using blastp (100\% identity). Taxonomy for the remaining de-replicated transcripts was inferred by blasting against the NCBI nr database and comparing the results with the taxonomic assignment by GhostKOALA.

\section{Additional files}

Additional file 1: Figure S1. a) Nitrate and chloride ion concentrations measured in the brine and pore water samples. b) Inorganic carbon content of dried sediment samples with depth. (PDF $83 \mathrm{~kb}$ )

Additional file 2: Figure S2. pH profile measured on two replicate sediment columns. (PDF $105 \mathrm{~kb}$ )

Additional file 3: Table S1. Grain size distribution of the top 12-cm sediment layer of Cock Soda Lake. Table S2. Element composition of dry sediment determined by inductively coupled plasma mass spectrometry (ICP-MS). Table S3. Metrics on the metagenomic raw sequence reads and assembled contigs obtained from Cock Soda Lake in 2016. Table S4. Metrics on the metatranscriptomic raw sequence reads and assembled transcripts obtained from the top 2-cm sediment layer from Cock Soda Lake in 2016. (PDF $120 \mathrm{~kb}$ )

Additional file 4: Dataset 1. Metrics and Genbank accession numbers on the obtained metagenome-assembled genomes (MAGs). The total size 
of the MAG (Mb), the number of contains (\# Contigs), the contig N50 $(\mathrm{kb})$, maximum contig length (kb), estimated mean coverage, average $\mathrm{G}+\mathrm{C}$ mol\%, total number of 5S, $16 \mathrm{~S}$ and $23 \mathrm{~S}$ rRNAs, total number of tRNAs and estimated percentages of CheckM-completeness (Compl), CheckM-contamination (Cont), and strain heterogeneity (Str het) are given. The final given name used for the Genbank submission (NCBI organism name) was derived from the Genome Taxonomy Database (GTDP) classification according to [89] and where possible verified with the $16 \mathrm{~S}$ rRNA gene classification according to the SILVA database (see column "Proposed name (GTDB)"). For the latter, BLAST results are reported: taxonomy of the best hit, identity with this best hit (\%), e value of the match, the length of the query (number of nucleotides), and the coverage with the hit (\%). (XLSX $182 \mathrm{~kb})$

Additional file 5: Figure S3. Relative abundance of top 50 abundant genera in the top $4-\mathrm{cm}$ sediment layer of Cock Soda Lake identified by amplicon sequencing of $16 \mathrm{~S}$ rRNA genes and transcripts. (PDF $112 \mathrm{~kb}$ )

Additional file 6: Dataset 2. Phylogenetic tree of all bacterial MAGs obtained in this study and in [35] based on 16 ribosomal proteins. References included in the tree were obtained from [98]. (TRE $269 \mathrm{~kb}$ )

Additional file 7: Dataset 3. Species representative MAGs that encode for S-cycling marker genes. Basis for Fig. 3. KEGG number assignment, CheckM-completeness, and CheckM-contamination are given. $\mathrm{X}$, gene absent; $V$, gene present. (XLSX $53 \mathrm{~kb}$ )

Additional file 8: Figure S4. Rfam family assignment of metatranscriptomic reads originating from non-coding RNA (ncRNA). Only the percentage of reads (relative to the total of 136474149 reads assigned as ncRNA) for the top 10 abundant Rfam families is shown. OLE RNAs are widespread among thermophilic Firmicutes, including sulfidogens from the genera Desulfotomaculum, but their exact function remains unknown [99]. (PDF 88 kb)

Additional file 9: Figure S5. Functional classification of the KEGGannotated transcripts. (PDF $89 \mathrm{~kb}$ )

Additional file 10: Dataset 4. Presence-absence of marker genes for central metabolic pathways and environmentally relevant element transformations in a selection of MAGs. MAGs were selected based on the presence of markers for dissimilatory sulfur cycling. KEGG number assignment, CheckM-completeness, and CheckM-contamination, as well as species delineation (based on average nucleotide identity, see the "Methods" section) are given. X, gene absent; V, gene present. (XLSX 261 kb)

Additional file 11: Figure S6. Maximum likelihood tree showing the phylogeny of the large subunit of RubisCo found in the MAG of the putative photoautotrophic Gemmatimonadetes bacterium. (PDF $154 \mathrm{~kb}$ )

Additional file 12: FigureS7. Agarose gels showing the integrity of the total RNA used for metatranscriptomics sequencing (top 0-2-cm sediment layer) and amplicon sequencing of 16S rRNA gene transcripts (top 0-2-cm and 2-4 -cm sediment layers). (PDF $522 \mathrm{~kb}$ )

\section{Acknowledgements}

We would like to acknowledge Dr. Olga Samylina, Gennadiy Borisenko, and Dr. Tatyana Khizhniak for the technical support during the fieldwork campaign. We like to thank Dr. Harm van der Geest for his help with the setup of the facilities for the microsensor measurements. We like to acknowledge Dr. Timothy Ferdelman and Kirsten Imhoff for their assistance with the inorganic sulfur compound quantification (IC and UPLC). We especially like to thank Dr. Ferdelman for revising the draft version of the manuscript before the initial submission.

\section{Authors' contributions}

Under the supervision of DYS and GM, CDV defined the research goals, conducted the fieldwork and laboratory experiments (thiosulfate amendments and microsensor measurements), prepared the samples for sequencing and chemical analysis, and performed the bioinformatics analysis. MM, A-SA, and RG assisted CDV with the bioinformatic analysis. CB assisted CDV during the fieldwork and sample preparation for sequencing. $\mathrm{RH}$ determined the general sediment characteristics. DYS measured the methane and iron sulfide concentrations. CDV was responsible for the liquid chromatography (IC and UPLC). CDV is the primary author of this manuscript and prepared the main figures with the help from MM. All authors read and approved the final manuscript.

\section{Funding}

CDV, CB, and GM were supported by the ERC Advanced Grant PARASOL (No. 322551). MM was supported by the Czech Academy of Sciences (Postdoc program PPPLZ application number L200961651). A-SA and RG were supported by the research grant 17-04828S from the Grant Agency of the Czech Republic. A-SA was additionally supported by the Czech Academy of Sciences (MSM200961801). DS was supported by SYAM-Gravitation Program of the Dutch Ministry of Education and Science (grant 24002002), in part by the Russian Foundation for Basic Research (RFBR 19-04-00401), and by the Russian Ministry of Science and Higher Education.

\section{Availability of data and materials}

All raw sequence reads from the metagenomes, metatranscriptome, and 165 rRNA gene and transcript amplicon sequencing were deposited to the NCBI Sequence Read Archive (SRA) under the accession number SRP144042 [46]. The final 1032 MAGs obtained in this study have been deposited as wholegenome shotgun projects at DDBJ/ENA/GenBank, and accession numbers are listed in Additional file 4: Dataset 1 (BioProject ID PRJNA453733) [40]. All versions described in this paper are version XXXX01000000. The transcripts assembled from the metatranscriptome (DOl:https://doi.org/10.21942/uva.781 9565) [47] and supporting phylogenetic analyses are available through figshare (DOl:https://doi.org/10.21942/uva.c.4594961) [93]. All other datasets generated or analyzed during this study, such as sequence annotations and protein alignments constructed for phylogenetic trees, are available from the corresponding author on reasonable request.

\section{Ethics approval and consent to participate}

Not applicable.

\section{Consent for publication}

Not applicable.

\section{Competing interests}

The authors declare that they have no competing interests.

\section{Author details}

${ }^{1}$ Microbial Systems Ecology, Department of Freshwater and Marine Microbiology, Institute for Biodiversity and Ecosystem Dynamics, University of Amsterdam, P.O. Box 94240, 1090 GE Amsterdam, the Netherlands. ${ }^{2}$ Department of Aquatic Microbial Ecology, Institute of Hydrobiology, Biology Centre of the Academy of Sciences of the Czech Republic, České Budějovice, Czech Republic. ${ }^{3}$ Department of Ecosystem \& Landscape Dynamics, Institute for Biodiversity and Ecosystem Dynamics, University of Amsterdam, Amsterdam, the Netherlands. 'Winogradsky Institute of Microbiology, Research Centre of Biotechnology, Russian Academy of Sciences, Moscow, Russian Federation. ${ }^{5}$ Department of Biotechnology, Environmental Biotechnology, Delft University of Technology, Delft, the Netherlands.

Received: 3 April 2019 Accepted: 9 August 2019

Published online: 22 August 2019

\section{References}

1. Wacey D, Kilburn MR, Saunders M, Cliff J, Brasier MD. Microfossils of sulphurmetabolizing cells in 3.4-billion-year-old rocks of Western Australia. Nat Geosci. 2011;4:698-702. https://doi.org/10.1038/ngeo1238.

2. Martin W, Baross J, Kelley D, Russell MJ. Hydrothermal vents and the origin of life. Nat Rev Microbiol. 2008;6:805-14. https://doi.org/10.1038/ nrmicro1991.

3. Canfield DE. The evolution of the sulfur cycle. Am J Sci. 1999:299:697-723. https://doi.org/10.2475/ajs.299.7-9.697.

4. Meier DV, Pjevac P, Bach W, Hourdez S, Girguis PR, Vidoudez C, et al. Niche partitioning of diverse sulfur-oxidizing bacteria at hydrothermal vents. ISME J. 2017;11:1545-58. https://doi.org/10.1038/ismej.2017.37.

5. Jørgensen BB. Mineralization of organic matter in the sea bed-the role of sulphate reduction. Nature. 1982;296:643-5. https://doi.org/10.1038/2 96643a0

6. Schagerl M. Soda Lakes of East Africa. Cham. 2016. https://doi.org/10.1007/ 978-3-319-28622-8.

7. Sorokin DY, Berben T, Melton ED, Overmars L, Vavourakis CD, Muyzer G. Microbial diversity and biogeochemical cycling in soda lakes. Extremophiles. 2014;18:791-809. https://doi.org/10.1007/s00792-014-0670-9. 
8. Sorokin DY, Kuenen JG, Muyzer G. The microbial sulfur cycle at extremely haloalkaline conditions of soda lakes. Front Microbiol. 2011;2:44. https://doi. org/10.3389/fmicb.2011.00044.

9. Sorokin DY, Banciu H, Robertson LA, Kuenen JG, Muntyan MS, Muyzer G. Halophilic and haloalkaliphilic sulfur-oxidizing bacteria. In: The prokaryotes. Berlin: Springer Berlin Heidelberg; 2013. p. 529-54. https://doi.org/10.1007/ 978-3-642-30141-4_77.

10. Sorokin DY, Banciu HL, Muyzer G. Functional microbiology of soda lakes. Curr Opin Microbiol. 2015;25:88-96. https://doi.org/10.1016/J.MIB.2015.05.004.

11. Sorokin DY. Anaerobic haloalkaliphiles. In: Encyclopedia of life sciences. Chichester: Wiley; 2017. p. 1-16. https://doi.org/10.1002/9780470015902. a0027654.

12. Oren A. The family Ectothiorhodospiraceae. In: The prokaryotes. Berlin: Springer Berlin Heidelberg; 2014. p. 199-222. https://doi.org/10.1007/ 978-3-642-38922-1_248.

13. Sorokin DY, Messina E, La Cono V, Ferrer M, Ciordia S, Mena MC, et al. Sulfur respiration in a group of facultatively anaerobic natronoarchaea ubiquitous in hypersaline soda lakes. Front Microbiol. 2018;9:2359. https://doi.org/10.33 89/fmicb.2018.02359.

14. Koch T, Dahl C. A novel bacterial sulfur oxidation pathway provides a new link between the cycles of organic and inorganic sulfur compounds. ISME J. 2018;12:2479-91. https://doi.org/10.1038/s41396-018-0209-7.

15. Brito JA, Sousa FL, Stelter M, Bandeiras TM, Vonrhein C, Teixeira M, et al. Structural and functional insights into sulfide:quinone oxidoreductase. Biochemistry. 2009;48:5613-22. https://doi.org/10.1021/bi9003827.

16. Thorup C, Schramm A, Findlay AJ, Finster KW, Schreiber L. Disguised as a sulfate reducer: growth of the deltaproteobacterium Desulfurivibrio alkaliphilus by sulfide oxidation with nitrate. MBio. 2017;8:1-9. https://doi. org/10.1128/mBio.00671-17.

17. Wasmund K, Mußmann M, Loy A. The life sulfuric: microbial ecology of sulfur cycling in marine sediments. Environ Microbiol Rep. 2017;9:323-44. https://doi.org/10.1111/1758-2229.12538.

18. Poser A, Lohmayer R, Vogt C, Knoeller K, Planer-Friedrich B, Sorokin D, et al. Disproportionation of elemental sulfur by haloalkaliphilic bacteria from soda lakes. Extremophiles. 2013;17:1003-12. https:/doi.org/10.1007/s00792-013-0582-0.

19. Friedrich CG, Rother D, Bardischewsky F, Quentmeier A, Fischer J. Oxidation of reduced inorganic sulfur compounds by bacteria: emergence of a common mechanism? App/ Environ Microbiol. 2001;67:2873-82. https://doi. org/10.1128/AEM.67.7.2873-2882.2001.

20. Ghosh W, Dam B. Biochemistry and molecular biology of lithotrophic sulfur oxidation by taxonomically and ecologically diverse bacteria and archaea. FEMS Microbiol Rev. 2009;33:999-1043. https://doi.org/10.1111/j.1574-6976.2 009.00187.x

21. Friedrich CG, Quentmeier A, Bardischewsky F, Rother D, Kraft R, Kostka S, et al. Novel genes coding for lithotrophic sulfur oxidation of Paracoccus pantotrophus GB17. J Bacteriol. 2000;182:4677-87.

22. Dahl C, Engels S, Pott-Sperling AS, Schulte A, Sander J, Lubbe Y, et al. Novel genes of the dsr gene cluster and evidence for close interaction of Dsr proteins during sulfur oxidation in the phototrophic sulfur bacterium Allochromatium vinosum. J Bacteriol. 2005;187:1392-404. https://doi.org/1 0.1128/JB.187.4.1392-1404.2005

23. Müller FH, Bandeiras TM, Urich T, Teixeira M, Gomes CM, Kletzin A. Coupling of the pathway of sulphur oxidation to dioxygen reduction: characterization of a novel membrane-bound thiosulphate:quinone oxidoreductase. $\mathrm{Mol}$ Microbiol. 2004;53:1147-60. https://doi.org/10.1111/j.1365-2958.2004.04193.x.

24. Brito JA, Denkmann K, Pereira IAC, Archer M, Dahl C. Thiosulfate dehydrogenase (TsdA) from Allochromatium vinosum. J Biol Chem. 2015;290: 9222-38. https://doi.org/10.1074/jbc.M114.623397.

25. Denkmann K, Grein F, Zigann R, Siemen A, Bergmann J, van Helmont S, et al. Thiosulfate dehydrogenase: a widespread unusual acidophilic c-type cytochrome. Environ Microbiol. 2012;14:2673-88. https://doi.org/10.1111/ j.1462-2920.2012.02820.x

26. Sorokin DY. Oxidation of inorganic sulfur compounds by obligately organotrophic bacteria. Microbiology. 2003;72:641-53. https://doi.org/10.1 023/B:MICI.0000008363.24128.e5.

27. Burns JL, DiChristina TJ. Anaerobic respiration of elemental sulfur and thiosulfate by Shewanella oneidensis MR-1 requires psrA, a homolog of the phsA gene of Salmonella enterica Serovar Typhimurium LT2. Appl Environ Microbiol. 2009;75:5209-17. https://doi.org/10.1128/AEM.00888-09.

28. Hedderich R, Klimmek O, Kröger A, Dirmeier R, Keller M, Stetter KO. Anaerobic respiration with elemental sulfur and with disulfides. FEMS
Microbiol Rev. 1998;22:353-81. https://doi.org/10.1111/J.1574-6976.1998. TB00376.X.

29. Berks BC, Hinsley AP. Specificity of respiratory pathways involved in the reduction of sulfur compounds by Salmonella enterica. Microbiology. 2002; 148:3631-8. https://doi.org/10.1099/00221287-148-11-3631.

30. Melton ED, Sorokin DY, Overmars L, Chertkov O, Clum A, Pillay M, et al. Complete genome sequence of Desulfurivibrio alkaliphilus strain AHT2T, a haloalkaliphilic sulfidogen from Egyptian hypersaline alkaline lakes. Stand Genomic Sci. 2016;11:67. https://doi.org/10.1186/s40793-016-0184-4.

31. Foti MJ, Sorokin DY, Zacharova EE, Pimenov NV, Kuenen JG, Muyzer G. Bacterial diversity and activity along a salinity gradient in soda lakes of the Kulunda Steppe (Altai, Russia). Extremophiles. 2008;12:133-45. https://doi. org/10.1007/s00792-007-0117-7.

32. Tourova TP, Slobodova NV, Bumazhkin BK, Kolganova TV, Muyzer G, Sorokin DY. Analysis of community composition of sulfur-oxidizing bacteria in hypersaline and soda lakes using soxB as a functional molecular marker. FEMS Microbiol Ecol. 2013;84:280-9. https://doi.org/10.1111/1574-6941.12056.

33. Edwardson CF, Hollibaugh JT. Metatranscriptomic analysis of prokaryotic communities active in sulfur and arsenic cycling in Mono Lake, California, USA. ISME J. 2017;11:2195-208. https://doi.org/10.1038/ismej.2017.80.

34. Vavourakis CD, Ghai R, Rodriguez-Valera F, Sorokin DY, Tringe SG, Hugenholtz $P$, et al. Metagenomic insights into the uncultured diversity and physiology of microbes in four hypersaline soda lake brines. Front Microbiol. 2016;7:211. https://doi.org/10.3389/fmicb.2016.00211.

35. Vavourakis CD, Andrei A-S, Mehrshad M, Ghai R, Sorokin DY, Muyzer G. A metagenomics roadmap to the uncultured genome diversity in hypersaline soda lake sediments. Microbiome. 2018;6:168. https://doi.org/10.1186/s4016 8-018-0548-7.

36. van Breugel F, Dickinson MH. Superhydrophobic diving flies (Ephydra hians) and the hypersaline waters of Mono Lake. Proc Natl Acad Sci. 2017;114: 13483-8. https://doi.org/10.1073/pnas.1714874114.

37. Borsodi AK, Korponai K, Schumann P, Spröer C, Felföldi T, Márialigeti K, et al. Nitrincola alkalilacustris sp. nov. and Nitrincola schmidtii sp. nov., alkaliphilic bacteria isolated from soda pans, and emended description of the genus Nitrincola. Int J Syst Evol Microbiol. 2017;67:5159-64. https://doi.org/10.1099/ ijsem.0.002437.

38. Boden R, Scott KM, Williams J, Russel S, Antonen K, Rae AW, et al. An evaluation of Thiomicrospira, Hydrogenovibrio and Thioalkalimicrobium: reclassification of four species of Thiomicrospira to each Thiomicrorhabdus gen. nov. and Hydrogenovibrio, and reclassification of all four species of Thioalkalimicrobium to Thiomic. Int J Syst Evol Microbiol. 2017;67:1140-51. https://doi.org/10.1099/ijsem.0.001855.

39. Wasmund K, Schreiber L, Lloyd KG, Petersen DG, Schramm A, Stepanauskas $\mathrm{R}$, et al. Genome sequencing of a single cell of the widely distributed marine subsurface Dehalococcoidia, phylum Chloroflexi. ISME J. 2014;8:38397. https://doi.org/10.1038/ismej.2013.143.

40. Vavourakis CD, Mehrshad M, Balkema C, van Hall R, Andrei A-S, Ghai R, et al. MAGs from Cock Soda Lake. 2019. https://www.ncbi.nlm.nih.gov/ nuccore?term $=453733 \% 5$ BBioProject $\% 5 D$.

41. Timmers PHA, Vavourakis CD, Kleerebezem R, Damsté JSS, Muyzer G, Stams AJM, et al. Metabolism and occurrence of methanogenic and sulfate-reducing syntrophic acetate oxidizing communities in haloalkaline environments. Front Microbiol. 2018;9:1-18. https://doi.org/10.3389/fmicb.2018.03039.

42. Namsaraev Z, Samylina O, Sukhacheva M, Borisenko G, Sorokin DY, Tourova T. Effect of salinity on diazotrophic activity and microbial composition of phototrophic communities from Bitter-1 soda lake (Kulunda Steppe, Russia). Extremophiles. 2018;22:651-63. https://doi.org/10.1007/s00792-018-1026-7.

43. Samylina OS, Sapozhnikov FV, Gainanova OY, Ryabova AV, Nikitin MA, Sorokin DY. Algo-bacterial communities of the Kulunda steppe (Altai Region, Russia) Soda Lakes. Microbiology. 2014;83:849-60. https://doi.org/1 $0.1134 /$ S0026261714060162.

44. Sorokin DY, van Pelt S, Tourova TP, Evtushenko LI. Nitriliruptor alkaliphilus gen. nov., sp. nov., a deep-lineage haloalkaliphilic actinobacterium from soda lakes capable of growth on aliphatic nitriles, and proposal of Nitriliruptoraceae fam. nov. and Nitriliruptorales ord. nov. Int J Syst Evol Microbiol. 2009;59:248-53. https://doi.org/10.1099/ijs.0.002204-0.

45. Vavourakis CD, Mehrshad M, Balkema C, van Hall R, Andrei A-S, Ghai R, et al. MAGs from hypersaline soda lake sediments. 2019. https://www.ncbi.nlm. nih.gov/bioproject/?term=PRJNA434545.

46. Vavourakis CD, Mehrshad M, Balkema C, van Hall R, Andrei A-S, Ghai R, et al. Raw sequence reads metagenomes, metatranscriptome and 16S rRNA gene 
and transcript amplicon sequencing. 2018. https://www.ncbi.nlm.nih.gov/ Traces/study/?acc=PRJNA453733.

47. Vavourakis CD, Mehrshad M, Balkema C, van Hall R, Andrei A-S, Ghai R, et al. Assembled contigs metatranscriptome. 2019.

48. Pereira IAC, Ramos AR, Grein F, Marques MC, da Silva SM, Venceslau SS. A comparative genomic analysis of energy metabolism in sulfate reducing Bacteria and Archaea. Front Microbiol. 2011;2:69. https://doi.org/10.3389/ fmicb.2011.00069.

49. Czyzewski BK, Wang D-N. Identification and characterization of a bacterial hydrosulfide ion channel. Nature. 483:494. doi:https://doi.org/10.1038/ NATURE10881.

50. Sorokin DY, Tourova TP, Braker G, Muyzer G. Thiohalomonas denitrificans gen. nov., sp. nov. and Thiohalomonas nitratireducens sp. nov., novel obligately chemolithoautotrophic, moderately halophilic, thiodenitrifying Gammaproteobacteria from hypersaline habitats. Int J Syst Evol Microbiol. 2007;57:1582-9. https://doi.org/10.1099/ijs.0.65112-0.

51. Kopejtka K, Tomasch J, Zeng Y, Tichý M, Sorokin DY, Koblížek M. Genomic analysis of the evolution of phototrophy among haloalkaliphilic Rhodobacterales. Genome Biol Evol. 2017;9:1950-62. https://doi.org/10.1093/ gbe/evx141.

52. Hensel M, Hinsley AP, Nikolaus $T$, Sawers G, Berks BC. The genetic basis of tetrathionate respiration in Salmonella typhimurium. Mol Microbiol. 1999;32: 275-87. https://doi.org/10.1046/j.1365-2958.1999.01345.x.

53. Nolla-Ardèvol V, Strous M, Tegetmeyer HE. Anaerobic digestion of the microalga Spirulina at extreme alkaline conditions: biogas production, metagenome, and metatranscriptome. Front Microbiol. 2015:1-21. doi: https://doi.org/10.3389/fmicb.2015.00597.

54. Sorokin DY, Kuenen JG. Chemolithotrophic haloalkaliphiles from soda lakes. FEMS Microbiol Ecol. 2005;52:287-95.

55. Sorokin DY, Rusanov II, Pimenov N V., Tourova TP, Abbas B, Muyzer G. Sulfidogenesis under extremely haloalkaline conditions in soda lakes of Kulunda Steppe (Altai, Russia). FEMS Microbiol Ecol. 2010;73:no-no. doi: https://doi.org/10.1111/j.1574-6941.2010.00901.x.

56. Spang A, Saw JH, Jørgensen SL, Zaremba-Niedzwiedzka K, Martijn J, Lind AE, et al. Complex archaea that bridge the gap between prokaryotes and eukaryotes. Nature. 2015;521:173-9. https://doi.org/10.1038/nature14447.

57. Zeng Y, Feng F, Medova H, Dean J, Kobli ek M. Functional type 2 photosynthetic reaction centers found in the rare bacterial phylum Gemmatimonadetes. Proc Natl Acad Sci. 2014;111:7795-800. https://doi.org/1 0.1073/pnas.1400295111.

58. Dachev M, Bína D, Sobotka R, Moravcová L, Gardian Z, Kaftan D, et al. Unique double concentric ring organization of light harvesting complexes in Gemmatimonas phototrophica. PLOS Biol. 2017;15:e2003943. https://doi. org/10.1371/journal.pbio.2003943.

59. Chernousova E, Gridneva E, Grabovich M, Dubinina G, Akimov V, Rossetti S, et al. Thiothrix caldifontis sp. nov. and Thiothrix lacustris sp. nov., gammaproteobacteria isolated from sulfide springs. Int J Syst Evol Microbiol. 2009:59:3128-35. https://doi.org/10.1099/ijs.0.009456-0.

60. König S, Gros O, Heiden SE, Hinzke T, Thürmer A, Poehlein A, et al. Nitrogen fixation in a chemoautotrophic lucinid symbiosis. Nat Microbiol. 2017;2: 16193. https://doi.org/10.1038/nmicrobiol.2016.193.

61. Anantharaman K, Hausmann B, Jungbluth SP, Kantor RS, Lavy A, Warren $L A$, et al. Expanded diversity of microbial groups that shape the dissimilatory sulfur cycle. ISME J. 2018;12:1715-28. https://doi.org/10.103 8/s41396-018-0078-0.

62. Ma K, Schicho RN, Kelly RM, Adams MW. Hydrogenase of the hyperthermophile Pyrococcus furiosus is an elemental sulfur reductase or sulfhydrogenase: evidence for a sulfur-reducing hydrogenase ancestor. Proc Natl Acad Sci. 1993:90:5341-4. https://doi.org/10.1073/pnas.90.11.5341.

63. Liu X, Li M, Castelle CJ, Probst AJ, Zhou Z, Pan J, et al. Insights into the ecology, evolution, and metabolism of the widespread Woesearchaeotal lineages. Microbiome. 2018;6:102. https://doi.org/10.1186/s40168-018-0488-2.

64. Sorokin DY, Abbas B, Geleijnse M, Pimenov NV, Sukhacheva MV, van Loosdrecht MCM. Methanogenesis at extremely haloalkaline conditions in the soda lakes of Kulunda Steppe (Altai, Russia). FEMS Microbiol Ecol. 2015; 91:1-12. https://doi.org/10.1093/femsec/fiv016.

65. Lee KM, Adams M, Klassen JL. Evaluation of DESS as a storage medium for microbial community analysis. PeerJ. 2019;7:e6414. https://doi.org/10. 7717/peerj.6414.

66. Van Wesemael JC. De bepaling van het calciumcarbonaatgehalte van gronden. Chem Weekbl. 1955;51:35-6.
67. Zopfi J, Ferdelman TG, Fossing H. Distribution and fate of sulfur intermediates — sulfite, tetrathionate, thiosulfate, and elemental sulfur -in marine sediments. In: Amend JP, Edwards KJ, Lyons TW, editors. Sulfur biogeochemistry: past and present. Boulder: Geological Society of America; 2004. p. 97-116

68. Parada AE, Needham DM, Fuhrman JA. Every base matters: assessing small subunit rRNA primers for marine microbiomes with mock communities, time series and global field samples. Environ Microbiol. 2016;18:1403-14. https://doi.org/10.1111/1462-2920.13023.

69. Joshi NA, Fass J. Sickle: a sliding-window, adaptive, quality-based trimming tool for FastQ files. 2011. github.com/najoshi/sickle.

70. Quast C, Pruesse E, Yilmaz P, Gerken J, Schweer T, Yarza P, et al. The SILVA ribosomal RNA gene database project: improved data processing and web-based tools. Nucleic Acids Res. 2012;41:D590-6. https://doi. org/10.1093/nar/gks1219.

71. Andersen KSS, Kirkegaard RH, Karst SM, Albertsen M. ampvis2: an R package to analyse and visualise 165 rRNA amplicon data. bioRxiv. 2018:299537. doi: https://doi.org/10.1101/299537.

72. DOE JGI. BBDuk (BBDuk version 36.19). jgi.doe.gov/data-and-tools/bbtools/ bb-tools-user-guide/bbduk-guide/. Accessed 20 June 2017.

73. Li D, Liu C-M, Luo R, Sadakane K, Lam T-W. MEGAHIT: an ultra-fast singlenode solution for large and complex metagenomics assembly via succinct de Bruijn graph. Bioinformatics. 2015;31:1674-6. https://doi.org/10.1093/ bioinformatics/btv033.

74. Hyatt D, Chen G-L, LoCascio PF, Land ML, Larimer FW, Hauser LJ. Prodigal: prokaryotic gene recognition and translation initiation site identification. BMC Bioinformatics. 2010;11:119. https://doi.org/10.1186/1471-2105-11-119.

75. Lowe TM, Eddy SR. tRNAscan-SE: a program for improved detection of transfer RNA genes in genomic sequence. Nucleic Acids Res. 1997;25:955-64 http://www.ncbi.nlm.nih.gov/pubmed/9023104.

76. Kanehisa M, Sato Y, Morishima K. BlastKOALA and GhostKOALA: KEGG tools for functional characterization of genome and metagenome sequences. $J$ Mol Biol. 2016;428:726-31. https://doi.org/10.1016/j.jmb.2015.11.006.

77. Kang DD, Froula J, Egan R, Wang Z. MetaBAT, an efficient tool for accurately reconstructing single genomes from complex microbial communities. PeerJ. 2015;3:e1165. https://doi.org/10.7717/peerj.1165.

78. Vavourakis CD, Mehrshad M, Balkema C, van Hall R, Andrei A-S, Ghai R, et al. Raw sequence reads metagenomes soda lakes - T1Sed10. 2015. https:// www.ncbi.nlm.nih.gov/sra/SRX143969[accn].

79. Vavourakis CD, Mehrshad M, Balkema C, van Hall R, Andrei A-S, Ghai R, et al. Raw sequence reads metagenomes soda lakes - B1-Sed10. 2015. https:// www.ncbi.nlm.nih.gov/sra/SRX143981 [accn].

80. Vavourakis CD, Ghai R, Rodriguez-Valera F, Sorokin DY, Tringe SG, Hugenholtz P, et al. Raw sequence reads metagenomes soda lakes - T5Br10. 2015. https://www.ncbi.nlm.nih.gov/sra/SRX143970[accn].

81. Vavourakis CD, Ghai R, Rodriguez-Valera F, Sorokin DY, Tringe SG, Hugenholtz $\mathrm{P}$, et al. Raw sequence reads metagenomes soda lakes - PLBr10. 2015. https://www.ncbi.nlm.nih.gov/sra/SRX143961 [accn].

82. Vavourakis CD, Ghai R, Rodriguez-Valera F, Sorokin DY, Tringe SG, Hugenholtz $\mathrm{P}$, et al. Raw sequence reads metagenomes soda lakes - TcBr11. 2015. https://www.ncbi.nlm.nih.gov/sra/SRX143977[accn].

83. Vavourakis CD, Ghai R, Rodriguez-Valera F, Sorokin DY, Tringe SG, Hugenholtz $P$, et al. Raw sequence reads metagenomes soda lakes - B1Br10. 2015. https://www.ncbi.nlm.nih.gov/sra/SRX143971 [accn].

84. Vavourakis CD, Mehrshad M, Balkema C, van Hall R, Andrei A-S, Ghai R, et al. Raw sequence reads metagenomes soda lakes - CSSed10. 2015. https:// www.ncbi.nlm.nih.gov/sra/SRX143971 [accn].

85. Vavourakis CD, Mehrshad M, Balkema C, van Hall R, Andrei A-S, Ghai R, et al. Raw sequence reads metagenomes soda lakes - CSSed11. 2015. https:// www.ncbi.nlm.nih.gov/sra/SRX143986[accn].

86. Vavourakis CD, Mehrshad M, Balkema C, van Hall R, Andrei A-S, Ghai R, et al. Raw sequence reads metagenomes soda lakes - T3-Sed10. 2015. https:// www.ncbi.nlm.nih.gov/sra/SRX143967[accn]

87. Bushnell B, Egan R, Copeland A, Foster B, Clum A, Sun H, et al. BBMap: a fast, accurate, splice-aware aligner. 2014. https://doi.org/10.1186/1471-21 05-13-238.

88. Eren AM, Esen ÖC, Quince C, Vineis JH, Morrison HG, Sogin ML, et al. Anvi'o: an advanced analysis and visualization platform for 'omics data. PeerJ. 2015; 3:e1319. https://doi.org/10.7717/peerj.1319.

89. Parks DH, Chuvochina M, Waite DW, Rinke C, Skarshewski A, Chaumeil P-A, et al. A standardized bacterial taxonomy based on genome phylogeny 
substantially revises the tree of life. Nat Biotechnol. 2018;36:996. https://doi. org/10.1038/nbt.4229.

90. Klappenbach JA, Goris J, Vandamme P, Coenye T, Konstantinidis KT, Tiedje JM. DNA-DNA hybridization values and their relationship to whole-genome sequence similarities. Int J Syst Evol Microbiol. 2007;57:81-91. https://doi. org/10.1099/ijs.0.64483-0.

91. Huerta-Cepas J, Szklarczyk D, Forslund K, Cook H, Heller D, Walter MC, et al. eggNOG 4.5: a hierarchical orthology framework with improved functional annotations for eukaryotic, prokaryotic and viral sequences. Nucleic Acids Res. 2016:44:D286-93. https://doi.org/10.1093/nar/gkv1248.

92. Müller AL, Kjeldsen KU, Rattei T, Pester M, Loy A. Phylogenetic and environmental diversity of DsrAB-type dissimilatory (bi) sulfite reductases. ISME J. 2015;9:1152-65.

93. Vavourakis CD, Mehrshad M, Balkema C, van Hall R, Andrei A-S, Ghai R, et al. Metagenomes and metatranscriptomes shed new light on the microbialmediated sulfur cycle in a Siberian soda lake: Supplementary Electronic Files Online. 2019. doi:https://doi.org/10.21942/uva.c.4594961.

94. Langmead B, Salzberg SL. Fast gapped-read alignment with Bowtie 2. Nat Methods. 2012;9:357-9. https://doi.org/10.1038/nmeth.1923.

95. Kopylova E, Noé L, Touzet H. SortMeRNA: fast and accurate filtering of ribosomal RNAs in metatranscriptomic data. Bioinformatics. 2012;28:3211-7. https://doi.org/10.1093/bioinformatics/bts611.

96. Griffiths-Jones S, Moxon S, Marshall M, Khanna A, Eddy SR, Bateman A. Rfam: annotating non-coding RNAs in complete genomes. Nucleic Acids Res. 2004;33(Database issue):D121-4. https://doi.org/10.1093/nar/gki081.

97. Doe JGl. dedupe.sh. jgi.doe.gov/data-and-tools/bbtools/bb-tools-user-guide/ dedupe-guide/. Accessed 20 June 2017.

98. Hug LA, Baker BJ, Anantharaman K, Brown CT, Probst AJ, Castelle CJ, et al. A new view of the tree of life. Nat Microbiol. 2016;1:16048. https://doi.org/10.1 038/nmicrobiol.2016.48.

99. Harris KA, Zhou Z, Peters ML, Wilkins SG, Breaker RR. A second RNA-binding protein is essential for ethanol tolerance provided by the bacterial OLE ribonucleoprotein complex. Proc Natl Acad Sci. 2018;115:E6319-28. https:// doi.org/10.1073/pnas.1803191115.

\section{Publisher's Note}

Springer Nature remains neutral with regard to jurisdictional claims in published maps and institutional affiliations.

Ready to submit your research? Choose BMC and benefit from:

- fast, convenient online submission

- thorough peer review by experienced researchers in your field

- rapid publication on acceptance

- support for research data, including large and complex data types

- gold Open Access which fosters wider collaboration and increased citations

- maximum visibility for your research: over $100 \mathrm{M}$ website views per year

At $\mathrm{BMC}$, research is always in progress.

Learn more biomedcentral.com/submissions 